\title{
Impact of exercise training on symptoms of depression, physical activity level and social participation in people living with HIV/AIDS: A systematic review and meta-analysis
}

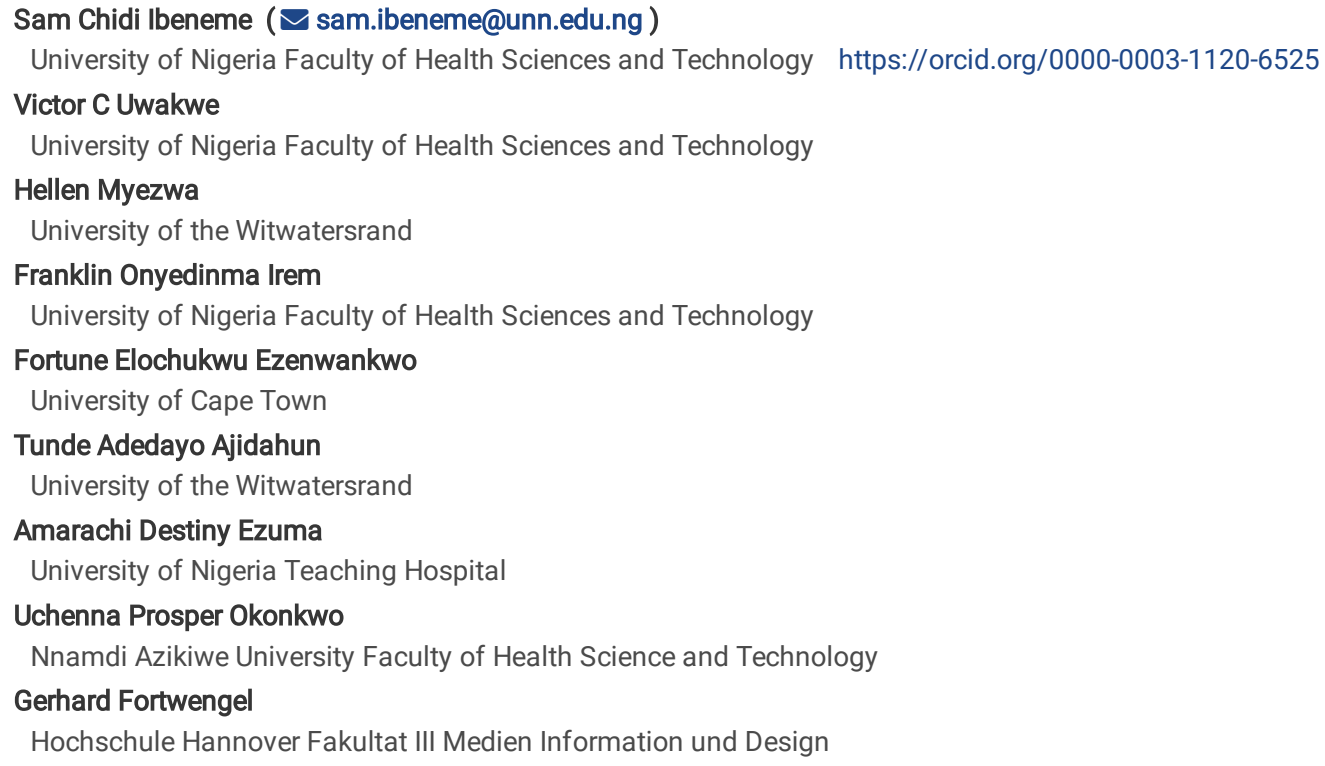




\section{Abstract}

Background: Symptoms of depression are prevalent in people living with human immune deficiency virus/acquired immune deficiency syndrome (PLWHA), and worsened by lack of physical activity/exercises, leading to restriction in social participation/functioning. This raises the question: What is the extent to which physical exercise training affected symptoms of depression, physical activity level (PAL) and social participation in PLWHA compared to other forms of interventions, usual care, or no treatment controls?

Objectives: To assess the impact of physical exercise training on symptoms of depression, PAL and social participation in PLWHA.

Data sources: Eight databases were searched up to July 2020, according to the Preferred Reporting Items for Systematic Review and Meta-Analysis (PRISMA) protocol.

Study eligibility criteria: Only randomised controlled trials involving adults who were either on HAART/HAART-naïve and reported in the English language, were included.

Data collection and analysis: Two independent reviewers determined the eligibility of the studies, extracted data, assessed their quality, and risk of bias using the Physiotherapy Evidence Database (PEDro) tool. Standardised mean difference (SMD) was used as summary statistics for the mean primary outcome (symptoms of depression) and secondary outcomes (PAL and social participation) since different measuring tools/units were used across the included studies. Summary estimates of effects were determined using a random-effects model $\left(\mathrm{I}^{2}\right)$.

Results: Thirteen studies met the inclusion criteria with 779 participants ( $\mathrm{n}=596$ participants on study completion) randomised into the study groups, comprising 378 males, 310 females and 91 participants with undisclosed gender, and with an age range of 18-86 years. Across the studies, aerobic or aerobic plus resistance exercises were performed 2-3 times/week, at 40-60 minutes/session, and for between 6-24 weeks, and the risk of bias varied from high to low. Comparing the intervention to control groups showed significant difference in the symptoms of depression (SMD $=-0.74,95 \%$ confidence interval $(C l)=-1.01,-0.48, p=<0.0002 ;\left.\right|^{2}=47 \% ; 5$ studies; 205 participants) unlike PAL (SMD $=0.98,95 \% C l=-0.25,2.17, p=0.11 ;\left.\right|^{2}=82 \% ; 2$ studies; 62 participants $)$ and social participation $\left(\mathrm{SMD}=0.04,95 \% \mathrm{Cl}=-0.65,0.73, \mathrm{p}=0.91 ; 1^{2}=90 \% ; 6\right.$ studies; 373 participants).

Conclusion: Physical exercise training could have an antidepressant-like effect in PLWHA but did not affect their PAL and social participation. However, the high heterogeneity in the included studies, imply that adequately powered RCTs with clinical/methodological similarity are required in future studies.

Registration number: INPLASY202040048

\section{Background}

People living with the human immune deficiency virus/Acquired immune deficiency syndrome (HIV/AIDS) (PLWHA) present with symptoms of psychological and physiological dysfunction $(1,2)$. The common physical symptoms of HIV include headache, pain, fatigue, nausea, diarrhoea, rash, lipodystrophy, and lipoatrophy $(1,2)$. These symptoms allude to multi-systemic alterations of the underlying biological processes due to either the HIV, antiretroviral therapy or both $(1,2)$. The subsequent disabilities which arise in PLWHA, involve physical, cognitive, mental and emotional signs (3). These disabilities negatively impact their coping strategies (3) with adverse implications for social interactions (4) and are worsened by lack of physical exercises and restriction in social participation (5), leading to multi-system impairments (6). Such impairments entail a decline in the PAL, thereby reinforcing the vicious cycle that advances the symptoms and disabilities associated with HIV. Therefore, exercise training, which may improve PAL, could address some social, mental and health-related challenges in PLWHA.

Physical activity indicates any human movement generated by skeletal muscle contraction at an increased metabolic cost, over a basal value at rest (5). Invariably, exercise is considered a subcategory of physical activity and a constituent of most activities of daily living (ADL), which is goal-directed and individual-specific. Hence, Caspersen, Powell (7) defined physical exercise as "physical activity that is planned, structured and repetitive, and has a final or an intermediate objective of improving or maintaining physical fitness". The U.S. Department of Health and Human Services (8) prescribed "150 minutes of moderate-intensity aerobic physical activity each week or 75 minutes of a vigorous-intensity aerobic-physical activity" or a comparable "combination of moderate and vigorous-intensity activity for adults (18-64 years)". Similarly, "10,000 steps/day is prescribed for beneficial health outcomes and physical fitness in healthy individuals" $(9,10)$. Exercises improve the PAL (11-13) and score in PLWHA $(14)$. It tunes up the musculature in boosting functional capacity and mobility, which is often restricted by the effects of HIV, HAART and associated complications (15). Importantly, exercises enhance recovery from disability; optimize mental, physical, economic or social outcomes for PLWHA (16).

Social participation relates to an individual's ability to fulfil personal goals and socially-defined roles in a community. The International Classification of Functioning, Disability and Health (ICF) defines participation as an individual's involvement in real-life situations relative to health conditions, body functions and structure, activities, and contextual environmental variables (17). Van As, Myezwa (18) reported that social participation is restricted in PLWHA due to disabilities, activity limitations, and participation restrictions arising from pain, weak muscle strength and fear of aggravating an existing pain in movementdriven activities, resulting in limited functional performance. Functional limitations, in PLWHA, influence care needs and capacity to perform social roles (such as engaging in a job) (19). Additionally, Myezwa, Stewart (20) observed that insufficient energy to participate in ADL or continue being socially active while coping with the disease is a recurring concern in PLWHA. Impairment and consequent disability arise from the side effects of HIV (21), and adverse drug interactions from polypharmacy, leading to fatigue/exhaustion $(22,23)$. Nevertheless, fatigue/low-energy is amenable to physical exercises $(24)$, which improve vitality, social participation (11-13), and minimises social dysfunction (25-27). Some studies found no effect of exercises on social participation and 
social contact $(28,29)$. However, considering that physical exercises relieve pain which is associated with social functioning $(30,31)$, and pain negatively impacts mental health (32), then exercises should have a bidirectional relationship with both pain and mental health.

Mental health is not only the absence of psychopathology but also the emotional, psychological and social well-being of an individual/group (33-35), and factors that negatively affect them will impair mental health. This explains why lipodystrophy and HAART are associated with neuropsychiatric disorders in PLWHA $(36,37)$. Lipodystrophy and lipoatrophy underlie the drastic weight loss, and unhealthy physical appearance in PLWHA, due to adipose tissue alterations, with a negative impact on self-image, self-esteem, and social functioning $(38,39)$. The sequelae involve poor mental health, lower functional quality of life, and lack of self-confidence, which limit $A D L$ and social participation $(40,41)$. The net effect is social withdrawal/isolation, which partly explains a higher prevalence of depression/mental disorders in PLWHA (42-44). However, exercise ameliorates the symptoms of severe depression in PLWHA (45). An epidemiological study demonstrates a negative association between regular physical activity and depressive disorders in adults (46). However, it is not a randomised control trial (RCT), and cannot determine causal relationships. Despite claims about the effects of physical exercises in PLWHA; it is unclear how much physical activity they engage in (15) or may require to ameliorate symptoms of depression, improve PAL, and social participation. Consequently, this review aimed to assess the impact of physical exercise training on symptoms of depression, PAL and social participation in PLWHA. The review question is What is the extent to which physical exercise training affected symptoms of depression, PAL and social participation in PLWHA compared to other forms of interventions, usual care, or no treatment controls?

\section{Methods}

A systematic review and meta-analyses were conducted, according to the Preferred Reporting Items for Systematic Review and Meta-Analysis (PRISMA) protocol. This systematic review was registered according to the International platform of registered systematic review and meta-analysis protocols (INPLASY register) on 9 April 2020 (registration number: INPLASY202040048).

\section{Eligibility Criteria}

The eligibility criteria applied in selecting the studies in the review are provided below:

Inclusion criteria:

Type of studies:

This review includes only original studies published in the English language, in peer-review journals and conferences' proceedings. Only studies based on RCTs design were included in the review when the following objectives were evaluated: effects of exercise training on depression, PAL and social participation/social functioning in PLWHA.

Types of Participant:

PLWHA, >18 years and are either on HAART or HAART-naïve. Though no specific limitation on the setting of the studies was considered, nevertheless, the included studies were mainly based in clinics/hospitals, home or community care settings.

\section{Types of Intervention:}

RCTs of physical exercise intervention for PLWHA were included in the review, which was not limited to any precise dosage, form, intensity, frequency and duration of intervention or follow-up period after the intervention. The exercise intervention may be clinic/hospital-based, community-based or home-based, and the exercise type may be aerobic, resistance exercise or a combination of both. Similarly, RCTs of resistance exercise intervention were not restricted to weight training, isometric and isotonic strengthening exercise in PLWHA.

\section{Types of Control:}

This review included studies that compared the effects of physical exercise training on symptoms of depression, PAL and social participation/social functioning to a control group receiving other forms of interventions, usual care, or no treatment.

\section{Type of Outcomes:}

\section{Primary outcomes}

Symptoms of depression: included a persistent feeling of sadness and loss of interest which

affects how an individual feels or thinks and behaves, leading to many emotional and physical problems. Several psychiatric rating scales are used for measuring this outcome namely - mood state questionnaire - POMS-30, General Health Questionnaire-28 - GHQ-28, Beck's Depression Inventory-BDI, and Centre for Epidemiologic Studies Depression Scale (CES-D).

\section{Secondary outcomes}

i. Physical activity level: This is operationalised as the quantity of an individual's day-to-day physical movement. It is used to gain a sense of the amount of energy expended (in terms of intensity and duration) in physical movements employed in the activities of daily living. It is measured using monitor-based 
devices or wearable technologies such as pedometers, accelerometers, or GPS units, and expressed using heart rate, pedometer step count per day, meters per second squared $\left(\mathrm{m} / \mathrm{s}^{2}\right)$ or in G-forces $(\mathrm{g})$, respectively.

ii. Social participation/Social functioning: Social participation is defined as the frequency of an individual's engagement in activities that afford interaction with other community dwellers within and outside the home. Social participation is also taken as social functioning which defines an individual's interactions with their environment and the ability to fulfil their social roles within such environments and responsibilities as work, social activities, and relationships with spouse/partners and family. This outcome is measured using functional performance-based instruments (using subscales within generalized scales) that include six types of activities: hobby, friendship, clubs, volunteer activities, community events and communication with family members and friends. The measuring instruments include 36-Item Short Form Survey (SF-36), The Medical Outcomes Study HIV Health Survey (MOS-HIV), Duke Activity Status Index [DASI], and The World Health Organization's Quality of Life HIV instrument-Brief (WHOQOL-HIV-BREF.

Studies were included regardless of whether an outcome of interest is the primary or secondary outcome in the include studies, so far as a clear analysis was carried out for each outcome. All outcome variables were collated as they were accounted for in individual studies, and the original description in those individual studies was not modified. Clinical results, detailed by individual studies were analysed and graded.

\section{Exclusion criteria:}

1. Studies without an exercise or physical activity intervention component.

2. Studies that were not up to 4 weeks duration.

3. Narratives review synthesis, systematic reviews, opinion papers, letters and any publication without primary data and/or explicit description of the methods.

4. In considering duplicate publications from the same study, the most recent or most comprehensive publication were

\section{Information sources and search strategy}

An extensive search strategy to identify eligible studies was implemented in two phases according to the PRISMA protocol, including; (i) the search of the bibliographic database and grey literature, and (ii) the selection of studies for inclusion based on eligibility criteria. Searches involved some combinations of search terms from medical subject headings (MeSH) and keywords with a combination of Boolean logic in the title, abstract and text for the population, intervention, control and outcomes, first in a pilot search to establish the sensitivity of the search strategy. The search strategy was used differently for the three selected study outcomes. PubMed search strategy is shown in Appendix I. This strategy was modified to the syntax and subject heading of other databases. Studies were searched in PubMed, Emcare, Cochrane Library, Embase, CINAHL, AMED, PsycINFO and MEDLINE. Additional searches were made from the reference list of identified studies. This procedure was implemented by the recommended guidelines of the Cochrane Handbook for Systematic Reviews (47), and advice for Health Care Review by the Centre for Reviews and Dissemination (48).

\section{Study record and Data management}

The search results were exported to the RefWorks ${ }^{T M}$ manager where the Checks for duplication of the identified studies were done. From RefWorks ${ }^{T M}$ manager, the bibliographic records were exported to Microsoft Excel 2007 to enable the organisation, and sorting of articles for inclusion into the study, based on specific eligibility criteria.

\section{Selection Process}

The screening was performed in two phases. The initial screening was conducted based on the title and abstract by V.U. (reviewer 1 ) to identify articles that met the eligibility criteria. I.F.O (reviewer 2) independently cross-checked the initial screening results. The two reviewers then read through the full text of selected studies for further screening, using the eligibility criteria. Differences in opinions at any stage regarding inclusion or exclusion were resolved by discussion and reflection or in consultation with D.I.S (reviewer 3 ) when needed to remove assessor bias. The reasons for excluding studies were adequately documented, and details of the study selection process are presented in Figure 1.

\section{Data collection Processes}

i. Quality appraisal of included studies: The PEDro scale for quality appraisal of clinical trials was used to appraise the quality and the risk of bias in the included studies. The PEDro scale was developed by Verhagen and colleagues (49). The scale contains a checklist of 10 items/questions, scored "yes" or "no" on the internal validity and statistical information provided in the study. In assessing the quality of each study, the total number of "yes" in the checklist are summed up and scored over 10 . The three categories for the quality of the study are defined as follows: - poor ( $\leq 3)$, fair/moderate quality (4-5), and high quality (6-10). Poor-quality study means that the study has a high risk of bias, while high-quality study means the study has a low risk of bias. Two reviewers made judgments regarding the risk of bias of each of the included studies, independent of each other. Areas of differences were resolved by discussion and reflection, or in consultation with the third reviewer. Appraisal of the quality of the included studies was carried out after study selection was completed during data extraction and synthesis.

ii. Data Item: Data from the following variables were collected in the selected studies including - authors reference, participants' characteristics (including age range, gender, sample size), study sample size (also groups sample size where available), components of the intervention, the intervention setting, who delivered the intervention, duration of intervention and follow-up (where available), control, attrition rate, outcome(s) assessed, the outcome(s) measuring methods/techniques and summary of results, conclusions and funding sources. 
The review manager (RevMan) was used to analyse the data from the included studies to provide an answer to the review question about the impact of physical exercise training on depression, PAL and social participation in PLWHA. For each of the study outcomes, the appropriate statistical techniques were applied. In the quantitative synthesis, the mean values of the outcomes, standard deviation, and the number of participants in the included studies were pooled. These were used to calculate the post-intervention standardised mean difference (SMD) for the variables according to the standard analysis procedure in the Cochrane meta-analyses. The SMD was applied where different outcome measuring tools/units were used in the included studies. For continuous variables, the weighted mean difference was utilised when outcomes are uniform, with a $95 \%$ confidence interval. The overall effects of the interventions were documented, evaluated and combined in a proof table. Interpretation of SMD followed: small $=0.00-0.39$, moderate $=0.40-0.70$, and large $=>0.70[53]$. Alpha was set at $\mathrm{p}<0.05$.

\section{Data and sensitivity analysis}

Characteristics of the retained studies were sorted by year of publication and presented in a tabular form providing information relating to authors' references, sample size, age, setting, data collection format, outcomes, components of the intervention, component of the control, format and provider of the intervention, intervention and follow-up periods, and results. Three meta-analyses to find pooled effect sizes across studies were undertaken, using a random-effects model. Cochrane's $\chi^{2}$ test ( $10 \%$ significance level) and Higgins $I^{2}$ were used for assessing the heterogeneity of the data for which values of $25 \%,>25-75 \%$, and $>75 \%$ indicate low, medium and high heterogeneity, as specified by the guidance provided in the Cochrane Handbook for Systemic Reviews of Interventions (48). Examination and documentation of outcomes were made using the primary outcome. Studies with clinical or methodological similarities in terms of design, intervention, and comparator(s) were pooled together for meta-analysis using a random-effects model. A narrative synthesis was applied for the interpretation of heterogeneous studies according to the recommendation of the Centre for Reviews and Dissemination to determine the relationship and results between and within the studies included in this review (47) PALSensitivity analysis was done after the primary quantitative synthesis to determine the effect that studies with a high risk of bias have on the general outcomes when they are excluded or included in the analysis.

\section{Result}

\section{Search result}

We carried out searches sequentially using the three primary outcomes (symptoms of depression, physical activity level and social participation) in the search strategy. The initial search yielded 3530 potential citations of which thirteen publications $(43,50-61)$ were considered eligible to be included in the review. (Figure 1) review. This review included five publications on depression $(43,50,53,56,60)$, seven publications on social participation/functioning ( $51,52,55$, $56,58,59,61)$ and two publications on PAL $(54,57)$. All the studies included in this review were conducted in the post-HAART era. Altogether, a total of 779 participants were involved across the thirteen studies included in this review.

\section{Reasons for exclusion}

Reasons for the exclusion of eight studies following full-text screening included: a pilot study $(\mathrm{n}=2)$, non-randomized control trials ( $\mathrm{n}=1$ ), had missing data whose author(s) failed to provide the missing data on request $(n=1)$, questionnaire bias $(n=1)$, included seronegative patients ( $n=1)$, used aerobic exercise training as control $(n=1)$ and did not study any of the outcome measures of interest $(n=1)$ (Figure 1$)$.

\section{Included studies}

Table 1 presents the study characteristics of the thirteen publications included in this review, and further details are provided below -

i. Depression: Five studies $(43,50,53,56,60)$ reported on the effect of an exercise intervention on depression. The duration of the interventions ranged from 6 weeks to 16 weeks, exercise session was from 15 to $60 \mathrm{~min}$, and the sessions per week were from 2 to 3 times per week. All the five included studies ( 43 , 50 , $53,56,60)$ did not provide any follow-up data. Three studies $(43,53,56)$ involved supervised aerobic and resistance exercise programme. Two studies $(50,60)$ involved supervised aerobic exercises only. For aerobic and resistance exercises: One study: Dianatinasab, Fararouei (53) had a "behavioural disease counselling and treatment" control group while Oliveira, Rosa (56) had a "recreational session consisting of stretches, gaming and dancing" for the control group. For aerobic exercises: Neidig, Smith (60) had a "usual activity" control, while Aweto, Aiyegbusi (50) had a control group who received "only counselling".

ii. Social Participation: Seven studies $(51,52,55,56,58,59,61)$ reported on the effects of an exercise intervention on social participation/functioning. The duration of the interventions ranged from 8 to 24 weeks, exercise session was from 10 to 60 min, and the sessions per week were from 1 to 5 times per week. None of the included studies provided any follow-up data. Four studies $(52,55,56,58)$ involved supervised aerobic and resistance/strengthening exercise programme. One study: Ogalha, Luz (55) involved supervised aerobic exercise-gym class and monthly nutritional counselling only. Another study: Maharaj and Chetty (61) involved aerobic exercises administered once per week and home programme (brisk walking, squatting and jogging), which was given twice per week. One study: Baigis, Korniewicz (51) involved a home-based workout programme using FM 340 Fitness Master Ski machine at 75-85\% Maximum Heart Rate thrice per week. For aerobic and resistance/strengthening exercises, one study: Jaggers, Hand (43) had a control group that engaged in unsupervised exercises; another study: Dianatinasab, Fararouei (53) had a "no exercise" control group. For aerobic exercises plus home programme (brisk walking, squatting and jogging): Maharaj and Chetty (61) had a control group that received heat therapy and shortwave diathermy and also, read magazines at home. For supervised gym plus monthly dieting counselling: Ogalha, Luz (55) had a control group that engaged in a discussion on dietary needs and recommendations, and received orientation on the importance of the regular physical activity. One study: Baigis, Korniewicz (51) had a control group that received usual care once a week. 
iii. Physical activity Level: Only two studies $(54,57)$ reported the effects of an exercise intervention on PAL. One study: McDermott, Zaporojan $(54)$ utilised aerobic exercises only and involved two supervised sessions and one unsupervised session. The aerobic exercises were given three times per week and had a "no intervention" control. Another study: Roos, Myezwa (57) utilised the pedometer-based walking programme and activity diary that included education material and documents for self-monitoring. However, the control group received only standard clinical management.

\section{Participants of the included studies}

The thirteen studies in this review involved 779 participants with the following gender distribution: males were 378 (48.52\%), females were 310 (39.79\%), while the gender of 91 participants (11.68\%) was undisclosed (Table 1 ). The male/female ratio across the studies is approximately $1.2: 1$. Only 596 (76.51\%) participants completed the studies while $183(23.49 \%)$ of them withdrew. The participants' age range was 18 years and above. Ten studies included participants on antiretroviral therapy $(43,50,52,55-61)$. However, Neidig, Smith (60) and Jaggers, Hand (43) reported that only $75 \%(35$ out of 60$)$ and $38.71 \%$ (36 out of 93) of the participants in their respective studies, were on ART. Nevertheless, four studies $(51,53,54)$ did not report the ART status of the participants. Similarly, ten studies did not report the staging of HIV in the participants $(43,52-59,61)$. In contrast, two studies $(50,60)$ reported that the participants' disease staging was category A and B" according to the US Centre for Disease Control classification of HIV infection or "asymptomatic, non-AIDS and symptomatic, non-AIDS stages', respectively. Similarly, one study (51), reported that all the participants were in the "category A" or "non-AIDS defining condition." However, one study (43) reported that the participants' HIV staging varied from "asymptomatic" (63\%), symptomatic (10\%), AIDS (25\%), and undisclosed staging (2\%)." Further details on the participants' characteristics in this review are provided below:

i. Depression: A total of 279 participants were included in the five publications $(43,50,53,56,60)$ that investigated the effects of physical exercises on depression (Table 1). On completion of the study, only 205 (73.48\%) participants were retained while 74 (26.52\%) participants withdrew. Participants were within the age range of $18-65$ years and comprised of 175 males, 60 females and 44 participants with an undisclosed gender. There is a male to female ratio of $3: 1$ in the review participants. None of the studies reported on whether the participants were on any form of antidepressants. The location of the studies varied as two studies were located in the USA $(43,60)$ while the rest were located in developing countries including Nigeria $(50)$, Iran $(53)$, and Brazil (56).

ii. Physical activity level: Two RCTs $(54,57)$ were included for studies that investigated the effects of physical exercise training on PAL in PLWHA and involved 97 participants, aged 18-65 years. They included 26 males, 69 females and 2 participants with an undisclosed gender. There is a male to female ratio of 1:2. On completion of the study, only 62 participants were retained while 35 participants withdrew. (Table 1).

iii. Social participation: Eight RCTs $(43,51,52,55,56,58-61)$ were included for social participation and involved 447 participants, aged $18-86$ years. They included 236 males, 166 females and 45 participants with an undisclosed gender. The male/female gender ratio is 1.4:1. On completion of the study, only 373 (83.45\%) participants were retained while 79 (17.67\%) participants withdrew. Two studies $(51,55,56,58)$ were located in Brazil, while two other studies $(51$, 58) were located in the USA. One study each was located in Hong Kong (52), South Arica (61), and Rwanda (59). (Table 1)

\section{Outcome of intervention}

Primary outcome:

i. Depression: The five included studies (Table 1) for depression assessed the participants using different measuring tools, namely: the profile of mood state questionnaire - POMS-30 (43, 60), General Health Questionnaire-28 - GHQ-28 (53), Beck's Depression Inventory-BDI (50, 56, 60), and Centre for Epidemiologic Studies Depression Scale (CES-D) (60).

\section{Secondary outcomes:}

ii. Social participation: Seven studies (Table 1) included in our review for social participation/functioning assessed social participation/functioning using different measuring tools including 36-Item Short Form Survey (SF-36) $(52,55,58,61)$, The Medical Outcomes Study HIV Health Survey (MOS-HIV) (51), Duke Activity Status Index [DASI]) (51), and The World Health Organization's Quality of Life HIV instrument-Brief (WHOQOL-HIV-BREF) (56, 59).

iii. Physical activity level: The two studies on PAL (Table 1) used different measuring tools. One study assessed physical activity using Actigraph GT3X+Tri Axis Accelerometer (54), while another assessed the same variable using The Yamax SW200 Pedometer (57).

\section{Quality appraisal and risk of bias assessment}

The risk of bias within the included studies is provided in Table 2. The major sources of bias in the included studies were performance bias (absence of subject and therapist blinding) in all the studies. Overall, based on the PEDro scale, ten studies $(76.92 \%)$ were judged as fair/moderate quality studies (43, 50 $55,58-60)$. Two studies $(15.38 \%)$ were judged as a high-quality study $(57,61)$ and one study $(7.69 \%)$ was judged as low quality $(56)$. Further details are provided below:

i. Eligibility criteria: The authors from the thirteen (13) studies included in our review reported on the Inclusion and Exclusion criteria used in recruiting and screening participants for their respective studies. Hence, the low risk of bias in this regard was evident in the whole studies.

ii. Random allocation: All the thirteen studies reported on using the randomization process to allocate their eligible participants to the different groups. Thus, they are free of selective reporting bias. 
iii. Concealment of allocation: There was lack of concealed allocation in eleven (43, 50,52-56, 58-61), detection bias for not reporting or providing enough information about blinding of the assessor in eleven studies $(43,50-56,58-60)$ and no Intention to treat analysis in ten $(43,50,52-56,58-60)$.

iv. Baseline comparability: There was baseline comparability in all the included studies except in two (15.38\%) studies by Chung, Lou (52) and Oliveira, Rosa (56). The two studies had study groups that were non-equivalent at baseline and were judged to have a high risk of bias in this regard.

v. Bias on blinding: Only two studies reported on the assessor and personnel blinding $(57,61)$ and were thus judged to have a low risk of bias in this regard.

vi. The bias of outcome measurement from <85\% of initial participants (incomplete outcome data): Four (30.77\%) studies reported adequate follow-up (52, 54 , $55,59)$ (Table 1). Overall, 183 out of 779 participants at baseline withdrew from the included studies accounting for $23.49 \%$ of the total number of participants. Withdrawal rates within individual studies ranged from $4.76 \%$ (52) to $60.7 \%$ (57) (Table 1). However, a moderate risk of attrition bias exists as eight $(43,50,51,53,56-58,61)$ of the thirteen included studies $(61.54 \%)$ reported withdrawal rates of $>15 \%$. However, one study $(59)$ reported that only three participants withdrew from the trials. Three $(23.08 \%)$ studies $(52,55,59)$ had a retention rate ranging from $90 \%$ to $97 \%$ due to low attrition, and therefore have a low risk of incomplete outcome bias. The withdrawal rate between comparison groups was similar in the included studies. Almost all the included studies cited participant(s) who did not comply with their exercise intervention or withdrew from the study. Eight studies $(51,52,54-56,58,59,61)$, gave information on adherence of participants to the exercise prescription, and which ranged from $60 \%$ (54) to $96.3 \%$ (52).

\section{Meta-analyses - Effects of interventions}

This review conducted three meta-analyses for studies on depression, PAL and social participation.

Depression:

Four $(43,50,53,56)$ (i.e. $80 \%)$ of the five studies $(43,50,53,56,60)$ included in this review, reported that physical exercise training significantly reduced the symptoms of depression in PLWHA. (Table 3). However, none of the studies provided information on whether the participants were on antidepressant medications or not. The physical exercise training prescriptions that ameliorated the symptoms of depression in the four studies were:

i. Combined exercise training (aerobic exercise: $40-45 \%$ Maximum Heart Rate for $45 \mathrm{mins}$ ) plus (Strength training exercise: 3 sets of 8 repetitions on $50-55 \%$ Repetitive Maximum for 15 mins); $3 x$ per week (53)

ii. Aerobic exercise training on a cycle ergometer at 50-60\% Heart Rate Reserve for 40 mins per session; $3 X$ per week for 6 weeks (50)

iii. Combined exercise training: aerobic exercise (30 mins on treadmill at 50-70\% Maximum Heart Rate) and resistance exercise (upper and lower-body resistance training: 1 set of 12 repetitions each on plate-loaded Hammer Strength Machines; upper anterior and posterior legs on Life Circuit Machines; free weights), 50 mins/session; $2 X /$ week for 6 weeks (43) and

iv. Combined exercise training (CET): aerobic exercise (15-20 mins of moderate-intensity at 50\%-65\% HRR), and strength training (15-20 mins of 8-15 MHR of 2-3 sets), 3 sessions per week for 16 weeks (56).

For the post-intervention analysis, we found a moderate standardized mean difference (SMD $=-0.63,95 \% \mathrm{Cl}:-0.96,-0.30)$ in favour of the exercise group in the random-effect model, for all the five studies included for depression $(43,50,53,56,60)$. Thus, physical exercise training had an overall significant effect $(Z$ $=3.73, p=<0.0002 ; 5$ studies; 205 participants) on symptoms of depression compared to the control group (Figure 2 ). The results demonstrate a significant trend towards a decrease in depressive symptoms for participants in the exercise compared to no exercise group; aerobic exercise compared to normal routine activity group; aerobic and resistance exercise compared to other control groups. Measuring tools used from the included studies were: GHQ-28; BDI; POMS-D; CES-D. (Table 1).

Physical activity level:

One $(57)$ of the two $(54,57)$ studies included in this review showed that exercises significantly improved the PAL in PLWHA between 0 - 6 months but not between 6 - 12 months (Table 4). For both studies, a large standardized mean difference (SMD $=0.98,95 \% \mathrm{Cl}$ : $-0.25,2.17$ ) in favour of the control group was found in the random-effect model for post-intervention values. Thus, physical exercise training had no overall significant effect $(Z=1.61, p=0.11 ; 2$ studies; 62 participants) on PAL in the experimental group compared to the control group. (Figure 3). Nevertheless, there was a consistent trend whereby the experimental groups recorded increased post-intervention PAL compared to the baseline values and vice versa in the control groups. The between-group comparison also showed that the post-intervention PAL was increased mainly in the experimental groups compared to the controls across the studies. Measuring tools used from the included studies were: Actigraph GT3X+Tri Axis Accelerometer; Yamax SW200 Pedometer. (Table 1).

\section{Social participation}

Only three $(42.86 \%)$ papers $(52,59,61)$ out of the seven included studies found a significant improvement in social participation in PLWHA due to physical exercise training (Table 5). In contrast, one paper (55) reported a significant decrease in social participation due to physical exercise training. The exercise training prescriptions that improved social participation in the three studies were:

i. Supervised combined aerobic and resistance training each at a moderate intensity of $50-70 \%$ MHR, for 45 mins per session, 2 sessions per week, for 8 weeks. (52) 
ii. Brisk walking for $15 \mathrm{mins}$ plus supervised aerobic and strengthening exercises at $45-75 \%$ of $\mathrm{MHR}$ for $45-60 \mathrm{mins}$ per session, (a total exercise duration of $1 \mathrm{hr}$ 30mins), 3 times per week, for 6 months. (59)

iii. Supervised aerobic exercise on a cycle ergometer and treadmill for 20 mins each with a rest period of 20 min once a week for 12 weeks, plus home programme: 10 mins of brisk walking, squatting and jogging 3 times per week for 12 weeks. (61)

The only exercise training prescription that showed significantly lower values for social participation than control was:

iv. Supervised gym class, for one hour, 3 times per week for 24 weeks plus monthly nutritional counselling. (55). However, the baseline data indicated that the intervention group also had significantly lower mean value for social participation compared to control.

Data from one paper by Baigis, Korniewicz (51) was not pooled for the meta-analysis because the standard deviation values were not provided by the journal editorial team (as the authors' contacts/email addresses were not provided in the publication) even after several correspondences. The six studies pooled for meta-analysis for social participation $(52,55,56,58,59,61)$, showed a small standardized mean difference $(\mathrm{SMD}=0.04,95 \% \mathrm{Cl}:-0.65,0.73)$ in favour of the control group in the random-effect model. Thus, physical exercise training had no significant effect ( $Z=0.11, p=0.91 ; 6$ studies; 368 participants) on social participation (Figure 4) among participants: in the exercise-group compared to no exercise group; aerobic exercise compared to normal routine activity group; aerobic gym class plus nutritional counselling to discussion on nutritional needs, and resistance exercise compared to other control groups. Measuring tools used in the included studies were: SF - 36 MOS, WHOQOL-HIV-BREF, WHOQOL-HIV, MOS HIV DASI. (Table 1).

\section{Heterogeneity}

There is moderate/medium heterogeneity in the data from the primary meta-analysis for depression $\left(I^{2}=47 \%, X^{2}=11.35, d f=6, p=0.08\right)(F i g u r e ~ 2-f o r e s t ~ p l o t)$. In contrast, there is a substantial/high heterogeneity from the data included in the meta-analysis for PAL $\left(I^{2}=82 \% ; X^{2}=1.61, d f=3, p<0.0008\right)(F i g u r e 3)$ and social participation $\left(I^{2}=90 \%, X^{2}=50.28, d f=5, p<0.00001\right)$ (Figure 4$)$, respectively.

\section{Sensitivity analysis}

\section{Depression}

After the primary meta-analysis, the first sensitivity analysis was done for depression that excluded trials by Oliveira, Rosa [61] because the control and exercise groups were non-equivalent at baseline. A significant effect was found (Figure 5) for exercise intervention (SMD= 0.74 [95\% Cl: $-1.01,-0.48], Z=5.55$; $p=0.00001)$, and the statistical heterogeneity was low $\left(I^{2}=0 \%, X^{2}=4.60, d f=5, p=0.47\right)$.

\section{Social participation}

After the primary meta-analysis (Figure 6), the sensitivity analysis was done for social participation that excluded three clinical trials in which the attrition rate was greater than $15 \%(56,58,61)$. No significant effect was found for physical exercise training (SMD= 0.65 [ $95 \% \mathrm{Cl}:-0.22,1.51], \mathrm{Z}=1.47 ; \mathrm{p}=0.14)$, and the statistical heterogeneity was high $\left(I^{2}=85 \%, X^{2}=13.07, d f=2, p=0.001\right)$.

\section{Discussion}

\section{Depression}

The combined evidence from the included studies seems to support the potential of physical exercise training to ameliorate the symptoms of depression in PLWHA. The synthesised evidence in this review revealed that aerobic exercises or combined (aerobic + resistance) exercises performed 2-3 times/week, at 40 - 60 minutes per session, and for between 6-24 weeks, effectively ameliorated the symptoms of depression in PLWHA. However, there were three times lesser females than males in the studies included in this review for depression. This might have some implications as a previous epidemiological study (62) in PLWHA revealed that symptoms of depression were more prevalent in women than men. It was found that the effect size in the meta-analyses is large, and therefore both males and females could have benefitted from the anti-depressant- effect of physical exercise training.

Additionally, given that the upper limit of age in the individual studies was not above 65 years, it is expected that age will not contribute significantly in the distribution of depressive symptoms among the participants. For depression, the sensitivity analysis excluded one study (56) for the non-equivalence of the control and exercise groups at baseline, and which resolved the medium heterogeneity of the primary meta-analysis. This suggests that some flaws exist in the randomisation process of the included studies, and need to be addressed in future studies. Given that the excluded study (56) was conducted in a developing country (Brazil), it is reasonable to assume that one of the challenges in conducting RCTs in resource-limited settings may be related to the availability of the technology for implementing randomisation, which may vary from the developed clime.

The findings of this study agree with the evidence from other systematic reviews $(1,3,63)$ that physical exercise training ameliorates the symptoms of depression in PLWHA. Besides, several systematic reviews $(42,64-66)$ present evidence that aerobic and resistance exercise intervention at various intensities have both stand-alone and combined positive effects on various aspects of mental health or psychological outcomes, such as depression (40, 65-67), hope, desire to continue living, (64) and health-related quality of life (64) in PLWHA. O'Brien, Tynan (3) presented evidence that performing an aerobic exercise or a 
combination of aerobic and resistance exercises, three times per week, for at least five weeks, leads to improvement in the symptoms of depression for adults with HIV.

A recent systematic review among PLWHA by Heissel, Zech (63) revealed that exercise has a large effect on depression ( $p=0.02)$ compared to controls. However, the review included nine studies on both conventional and unconventional exercises like yoga, which is considered a mind-body practice that integrates various body poses, breathing techniques, and utilises deep meditation (68). Invariably, the synthesised evidence by Heissel, Zech (63) cannot be strictly attributed to the effects of physical exercises alone, unlike our study which included only studies that investigated conventional exercises alone. Confounding factors may explain why the results from Heissel, Zech (63) have a higher statistical heterogeneity $\left(I^{2}=94 \%\right.$; $\left.p=0.02\right)$ and weakens our confidence in the estimate of effect. In contrast, our study has a lower heterogeneity and highlights the positive effect of exercise on symptoms of depression in a more homogenous sample of PLWHA. A lower heterogeneity increases our confidence in the estimate of effects of physical exercise training on symptoms of depression, and point to a significant role for physical exercise in the management of depression in PLWHA.

We further explored the literature for theoretical projections on the molecular and morphological basis for the antidepressant-like effect of exercise training on vital brain targets. The literature revealed that aerobic exercises could increase/improve the size (through neurogenesis) and function of the hippocampus thereby facilitating the brain control actions to minimise oxidative stress, attenuate inflammation (69) and ameliorate depression (70). In essence, exercise creates an opposing effect to the actions of the precursors of depression such as diminished neurogenesis, which in depressed individuals indicates hippocampal volumetric decreases (71), and susceptibility to experiencing a depression event (71). Running on a treadmill ameliorates depression through another mechanism involving the activation of the wingless (Wnt)-frizzled (Fz) signalling pathways (72), which is an upstream regulator/inhibitor of glycogen synthase kinase 3 (GSK 3) associated with depression (73). Increased expression of GSK-3 $\beta$ inhibits hippocampal neurogenesis and predisposes to depression (74). Other forms of exercise, especially resistance exercises, promotes the serotonin concentration which facilitates cell proliferation in the brain as well as neuro-plastic changes related to antidepressant effects (75). Also, the synaptic plasticity in the hippocampus-prefrontal cortex neuronal pathway, which is usually reduced by depression (76), is enhanced by exercises (70). Therefore, the significance of exercise in promoting synaptic plasticity (when antidepressant treatments fail to elicit increased cell proliferation), and sustaining brain function by activating Wnt signalling pathway, should not be overlooked in the management of depression in PLWHA.

\section{Physical Activity Level}

To the best of our knowledge, our study is the first systematic review conducted to demonstrate the effects of physical exercises on PAL in PLWHA. Though the meta-analysis from the two studies $(54,57)$ included for PAL showed no evidence that exercise trading improves the PAL in PLWHA, however, the findings of both studies revealed a consistent trend of improved post-intervention PAL (though not significant) among the experimental groups compared to the controls. Since the overall effect was not significant, it implies that physical exercise training may improve the PAL among PLWHA compared to no exercise group; aerobic exercise compared to normal routine activity group; aerobic and resistance exercise compared to other control groups. Nevertheless, there is a paucity of literature to form a scientific opinion on this matter, especially given that the two studies $(54,57)$ included in this review revealed a mixed result and therefore, lack of scientific consensus in this area.

McDermott, Zaporojan (54) reported no significant difference ( $p>0.05)$ in the PAL between the experimental and control groups after 16 weeks of exercise intervention. However, the study did not show any deterioration in the PAL as well. This implies that exercise intervention should have a protective effect in maintaining the PAL even if it does not significantly boost it. However, the results of the study should be interpreted with caution, because the sample size was small $(n=13)$ and the number of participants that completed the study was even smaller $(n=11)$. In essence, the study was underpowered to detect the statistical difference between the two groups. Invariably, there is a possibility that the true effects of exercise training on PAL in PLWHA were underestimated in the study due to type II error. More so, there is no report regarding the effect size to estimate the clinical significance of their findings. On the other hand, Roos, Myezwa (57) demonstrated that physical exercises significantly boosted the PAL of PLWHA within six months, but not beyond 6 - 12 months, whereby the compliance of the participants was lower than the first six months. Consequently, the findings demonstrate that unsupervised pedometer-based physical activity intervention can translate into tangible health benefits. This approach can be scaled-up to population-level to enable more active lifestyles for PLWHA if compliance is high as was the case from $0-6$ months. Nonetheless, it is not certain to what extent an unsupervised physical activity behavioural intervention approach will translate to a sustainable behavioural/lifestyle change considering that the participants recorded a low compliance level between 6 - 12 months. It probably explains why the post-intervention assessment of PAL showed no significant difference between the intervention and control groups.

The above findings highlight the need to utilise a common theoretical framework in physical activity review appointments, behavioural evaluations and goalsetting sessions when implementing any walking strategy to tackle the barriers to physical activity (77). Such theoretical framework enables the individuals to find barriers to walking, and make choices about how to change and enhance their walking behaviour (78) using various strategies. McDermott et al., 2017, and (57) did not apply this approach and seemed not to have implemented regular physical activity consultation sessions in their studies. This may partly explain why their studies were unable to find a significant difference in the PAL when the intervention group was compared to the control group. Notwithstanding this gap, the higher post-intervention PAL (though not significant) compared to the baseline value buttresses that physical exercise training 
boosts PAL in PLWHA. It reaffirms the evidence from McDermott, Zaporojan (54) that physical exercise training may have a protective effect in preventing a decline in the PAL of PLWHA even if it does not significantly increase the PAL. Importantly, the quality of the study by Roos, Myezwa (57) is high and the sample size $(n=84)$ is sufficiently powered to detect the difference between the groups but was affected by the high attrition rate (>15\%), or else, the findings would have been more significant. Overall, the paucity of literature, apart from the observed flaws in the two studies highlighted above, warrants the conduct of more high quality RCTs to determine the true estimate of effect of exercises on PAL in PLWHA, which is important to guide practice.

\section{Social Participation}

The available evidence demonstrates that the overall effect of exercise on social participation in PLWHA is not significant. However, we found a high attrition rate $(>15 \%)$ in all the included studies except three $(52,55,59)$, which may influence the outcome of the findings. Besides, the heterogeneity of the primary meta-analysis was high, and likewise the sensitivity analysis. Therefore, the data from the included studies do not seem to represent the true estimate of effect in a homogenous population of PLWHA. The heterogeneity of the data may be related to the diverse measuring tools for social participation/functioning employed across the included studies. Also, there is a selection bias as five $(52,55,56,59,61)$ of the seven papers did not implement the concealed allocation of the participants into the study groups. One of the studies with selection bias (55) reported a significant post-intervention decline in social participation in the intervention group than the control. However, the true estimate of effect is in doubt because the baseline value of social participation was significantly higher in the control group than the intervention group probably due to flaws in the randomisation procedure. Despite this limitation, exercise training did not reduce social participation below its baseline value in the intervention group. In essence, social participation neither deteriorated nor significantly improved among the exercising participants compared to control. Also, there is a likelihood that age might have some effects considering that older adults, up to 86 years of age, were involved in the included studies. Hence, the findings of our study do not agree with the results of previous studies in non-HIV infected population including a social experiment (79), a systematic review (80), descriptive cross-sectional study of individuals with disabilities (81), and an RCT of stroke survivours (82). Similarly, our study presented evidence at variance with the estimate of effect reported by another systematic review by Vancampfort, Stubbs (83) which included only studies involving PLWHA but was not restricted to RCTs.

All the cited studies above (79-83) identified a link between physical activity profile and social participation probably due to the effects of physical activity on mental health, especially mood (84-86). However, several limitations related to study design, and the involvement of mostly non-HIV infected population do not allow for the comparisons of the results between our study and the above-cited studies. Nevertheless, the importance of our study is supported by a previous view that HIV and rehabilitation research should focus on social participation (87). In an HIV population, it is especially important given that social stigmatization is problematic for PLWHA in different countries of the world (88). Social stigmatisation in PLWHA may lead to low self-esteem, mood disorders, and withdrawal from social activities or social isolation (88) resulting in a sedentary lifestyle or a decline in ambulatory function. Meanwhile, the ambulatory function is often restricted with polypharmacy, and a subsequent rise in complications associated with HIV infection (86) may add to the lack of restrictions in participation in physical (sedentary lifestyle) and social activities. The resulting multi-system (neurological, musculoskeletal, cardiopulmonary and metabolic) dysfunction may impair walking function, as well as compromise the quality of life (26). Limited social participation may also be related to a feeling of low self-esteem or rejection (89). Therefore, any intervention that may improve mental health by improving mood, and self-esteem in PLWHA, may also improve their physical functioning and likewise social participation. Knapen, Vancampfort (90) analysed four meta-analyses on the effects of physical exercise on mental and physical health in people with mental health problems. They found that exercise training resulted in a better quality of life, reduced emotional stress, enhanced self-esteem, and body image which have implications for a social relationship, and may have translational benefit for PLWHA. It emphasizes the point earlier made by Dianatinasab, Ghahri (91) that "keeping up physical activities and exercises are key strategies in medical and social care of PLWHA."

\section{Conclusion}

The evidence from this study suggests that physical exercise training has a potential benefit in ameliorating the symptoms of depression in PLWHA. The antidepressant-like effects of physical exercise modalities fit into the major treatment goals of PLWHA, especially the need to improve PAL [which may be impeded by depression (93)], recover strength and physical fitness (94) for productive social participation/functioning in a community. Therefore, the findings of this study recommend the integration of physical exercises into the routine care of PLWHA as a self-management strategy in the rehabilitation intervention to address disability and mental health needs of PLWHA. This also reiterates the recommendation of previous authors (87). Furthermore, the trend across the studies indicated that physical exercise training may prevent a decline but not significantly improve PAL and social participation in PLWHA.

\section{Implications for practice}

Evidence regarding the impact of exercise training on depression favours exercise when compared to control and suggests that the symptoms of depression are ameliorated by exercise training. These findings have important implications for practice, especially in sub-Saharan African where despite the existing evidence of the beneficial value of physical exercises/activity in improving mental health, yet physical exercises/activity is neglected as a routine rehabilitation modality in the mental healthcare systems (83). Importantly, mood disorders, which is common in PLWHA, have also been linked to poor adherence to medications and consequently, poor health outcomes (1, 2, 36 - 39). If physical activity/exercises ameliorate the symptoms of depression, it may also improve adherence to medication and likewise other related health outcomes. Therefore, public health policies and initiatives designed to increase participation in exercises may have the potential to improve mental health and general wellbeing among PLWHA.

\section{Implications for Research}

Across the included studies, there were notable potential sources of bias related to baseline comparability, incomplete outcome reporting, small sample size, short intervention duration, non-implementation of blinding of therapists and assessors. Also, diverse outcome measuring tools with different validity and reliability values were used in the included studies, which made data comparison across the studies more difficult. Some studies that evaluated the effects of exercises on depression and PAL were underpowered to detect the differences in the mean between the intervention and control groups. Some of the studies

Page $10 / 23$ 
did not provide information on the adherence rate and effect size to enable the estimation of the effect of the physical exercise training on the variables of interest in the PLWHA. Similarly, information on whether the participants were on antidepressant medications before the study was not provided in any of the studies. This makes it difficult to determine whether the antidepressant-like effects of physical exercises were independent or amplified in those taking antidepressant medications. These weaknesses may affect the validity of the findings of the various studies included in this review. Meanwhile, the paucity of RCTs on the impact of physical exercise training on PAL made it difficult to form a scientific opinion on its' effect.

The variability in the number of participants across the studies was high for social participation, ranging from 21 participants in one study (52) to 100 participants in another study (59). The same applied to studies on physical activity level which included participants ranging from 11 participants in one study (54) to 84 participants in another study (57). In contrast, the studies on depression had the least variability of participants, ranging from 40 participants in one study (53) to 93 participants in another study (43). This may contribute to the heterogeneity of the data across the studies, and might explain the substantial heterogeneity in the studies related to social participation and PAL. Additionally, the substantial heterogeneity suggests that there are some clinical or methodological differences, or both, across the studies included in the review. The is buttressed by the fact that the included studies showed variances in the study characteristics such as gender, location of study (developed versus developing countries), the type and dose of physical exercise training, measuring tools, sample size as well as non-equivalence of the study groups at baseline, and high attrition rates. Therefore, the variances also add to the clinical or methodological differences, and suggest some flaws in the trials design, documentation and implementation which should be addressed in future studies.

\section{Limitations}

There are several limitations to this study. First, the variables of interest are constructs, which are somewhat subjective and therefore difficult to measure objectively or accurately. Besides, the self-reported psychometric instruments used in data collection for the included studies are prone to recall bias. Importantly, the small sample size in some of the included studies will likely introduce bias for type II error, and likewise the small number of studies that were included in this review which met the eligibility criteria. The application of the standard mean difference provided a comparative basis to evaluate the effects of physical exercise training on the outcomes across the studies, where diverse measuring tools were used. However, there are difficulties applicable to the interpretation of the SMDs, which may limit the true estimation of the effects of the intervention across the studies. For instance, the interpretation of the SMDs varies across instruments depending on whether improvement in a given instrument is associated with lower or higher scores on the outcome measure (92). This is quite tricky when the SMDs have overlapping confidence intervals, which increases the failure to reject the null hypothesis. This also means an increase in type II error than the corresponding hypothesis test. Consequently, there is a need for more robust, rigorous and high-quality studies that will measure each variable of interest using more than one tool to enable realistic comparison of data across studies.

\section{List Of Abbreviations}

Human immune deficiency virus

Acquired immune deficiency syndrome

Antiretroviral therapy

Highly antiretroviral therapy

People living with HIV/AIDS

Risk of bias

Review Manager

Randomized control trials

Medical subject heading

Allied and Complementary Medicine Database

Cumulative Index to Nursing and Allied Health Literature

Excerpta Medica database

Allied and Complementary Medicine Database

Physiotherapy Evidence Database

Grading of Recommendations Assessment Development and Evaluation

International platform of registered systematic review and meta-analysis protocols

Preferred Reporting Items for Systematic Reviews and Meta-analyses
HIV

AIDS

ART

HAART

PLWHA

ROB

RevMan

RCTS

$\mathrm{MeSH}$

AMED

CINAHL

EMBASE

AMED

PEDro

GRADE

INPLASY

PRISMA 
standardised mean difference

Medical Outcomes Study

Nigeria Health Research Ethics Committee

World Health Organisation

Profile of Mood State Questionnaire - 30

General Health Questionnaire-28

Beck's Depression Inventory

Montreal cognitive assessment

Symptom Distress Scale

Perceived Stress Scale

Generalized Self-Efficacy Scale

Centre for Epidemiologic Studies Depression Scale

36-Item Short Form Survey

The Medical Outcomes Study HIV Health Survey

Duke Activity Status Index

The World Health Organization's Quality of Life HIV instrument-Brief

BREF

\section{Declarations}

\section{Ethics approval and consent to participate}

This is not applicable as human subjects are not involved.

\section{Consent to publish}

Not applicable

\section{Availability of data and materials}

The datasets supporting the conclusions of this article are available in the institutional University of Nigeria repository and will be made easily available on request when required.

\section{Competing interests}

The authors declare that there is no conflict of interest

\section{Funding}

This research received no specific grant from any funding agency in the public, commercial, or not-for-profit sectors

\section{Authors' Contributions}

$\mathrm{SCl}$ and UV conceived the study, participated in literature search and review, data extraction, study design and coordination, performed the statistical analysis, and helped draft the manuscript. EAD participated in data extraction and helped drafted the manuscript. EFE and IFO participated in literature search and review, statistical analysis and helped draft the manuscript. HM, AAT, OUP, and GF participated in the design of the study, coordination, and helped draft the manuscript. All authors read and approved the final manuscript.

\section{References}

1. Jaggers JR, Hand GA. Health benefits of exercise for people living with HIV: A review of the literature. American journal of lifestyle medicine. 2016;10(3):184-92.
Mos

WHO

GHQ-28

BDI

MOCA

SDS

PSS

GS-ES

CES-D

SF-36

MOS-HIV

DASI

WHOQOL-HIV-
NHREC

POMS-30 
2. Hicks C, Currier J, Sax P, Sherer R, Wanke C. Current management challenges in HIV: tolerability of antiretrovirals and metabolic complications. AIDS patient care and STDs. 2003;17(5):221-33.

3. O'Brien KK, Tynan A-M, Nixon SA, Glazier RH. Effectiveness of aerobic exercise for adults living with HIV: systematic review and meta-analysis using the Cochrane Collaboration protocol. BMC infectious diseases. 2016;16(1):182.

4. Philips H. Avoidance behaviour and its role in sustaining chronic pain. Behaviour research and therapy. 1987;25(4):273-9.

5. Fleury J, Lee SM. The social ecological model and physical activity in African American women. American journal of community psychology. 2006;37(12):141-54.

6. Nam H-S, Shin M-H, Zmuda J, Leung P, Barrett-Connor E, Orwoll E, et al. Race/ethnic differences in bone mineral densities in older men. Osteoporosis international. 2010;21(12):2115-23.

7. Caspersen CJ, Powell KE, Christenson GM. Physical activity, exercise, and physical fitness: definitions and distinctions for health-related research. Public health rep. 1985;100(2):126-31.

8. S. Department of Health and Human Services. 2008 Physical Activity Guidelines for Americans. Washington: U.S. Department of Health and Human Services; 2008.

9. Tudor-Locke C, Bassett DR. How many steps/day are enough? Sports medicine. 2004;34(1):1-8.

10. Tudor-Locke C, Craig CL, Brown WJ, Clemes SA, De Cocker K, Giles-Corti B, et al. How many steps/day are enough? For adults. International Journal of Behavioral Nutrition and Physical Activity. 2011;8(1):79.

11. Jaggers JR. Exercise and positive living in human immunodeficiency virus/AIDS. Nursing Clinics. 2018;53(1):1-11.

12. Penzak SR, Reddy YS, Grimsley SR. Depression in patients with HIV infection. American Journal of Health-System Pharmacy. 2000;57(4):376-86.

13. Zschucke E, Gaudlitz K, Ströhle A. Exercise and physical activity in mental disorders: clinical and experimental evidence. Journal of Preventive Medicine and Public Health. 2013;46(Suppl 1):S12.

14. Agin D, Gallagher D, Wang J, Heymsfield SB, Pierson Jr RN, Kotler DP. Effects of whey protein and resistance exercise on body cell mass, muscle strength, and quality of life in women with HIV. Aids. 2001;15(18):2431-40.

15. Tudor-Locke $\mathrm{C}$. Taking steps toward increased physical activity: Using pedometers to measure and motivate. President's Council on Physical Fitness and Sports Research Digest. 2002.

16. Warden SJ, Hill KM, Ferira AJ, Laing EM, Martin BR, Hausman DB, et al. Racial differences in cortical bone and their relationship to biochemical variables in Black and White children in the early stages of puberty. Osteoporosis International. 2013;24(6):1869-79.

17. World Health Organisation. International classification of functioning, disability and health: children and youth version: ICF-CY. Switzerland: World Health Organisation; 2017.

18. Van As M, Myezwa H, Stewart A, Maleka D, Musenge E. The International Classification of Function Disability and Health (ICF) in adults visiting the HIV outpatient clinic at a regional hospital in Johannesburg, South Africa. AIDS Care. 2009;21(1):50-8.

19. Crystal S, Fleishman JA, Hays RD, Shapiro MF, Bozzette SA. Physical and role functioning among persons with HIV: results from a nationally representative survey. Medical care. 2000:1210-23.

20. Myezwa H, Stewart A, Musenge E, Nesara P. Assessment of HIV-positive in-patients using the international classification of functioning, disability and health (ICF) at Chris Hani Baragwanath Hospital, Johannesburg. African Journal of AIDS Research. 2009;8(1):93-105.

21. Sarna L, van Servellen G, Padilla G, Brecht ML. Quality of life in women with symptomatic HIV/AIDS. Journal of Advanced Nursing. 1999;30(3):597-605.

22. Moyle GJ, Gazzard BG. A risk-benefit assessment of HIV protease inhibitors. Drug Safety. 1999;20(4):299-321.

23. Siefried KJ, Mao L, Cysique LA, Rule J, Giles ML, Smith DE, et al. Concomitant medication polypharmacy, interactions and imperfect adherence are common in Australian adults on suppressive antiretroviral therapy. AIDS (London, England). 2018;32(1):35.

24. Webel AR, Perazzo J, Decker M, Horvat-Davey C, Sattar A, Voss J. Physical activity is associated with reduced fatigue in adults living with HIV/AIDS. Journal of advanced nursing. 2016;72(12):3104-12.

25. Galantino ML, Shepard K, Krafft L, Laperriere A, Ducette J, Sorbello A, et al. The effect of group aerobic exercise and t'ai chi on functional outcomes and quality of life for persons living with acquired immunodeficiency syndrome. Journal of Alternative \& Complementary Medicine: Research on Paradigm, Practice, and Policy. 2005;11(6):1085-92.

26. Ibeneme SC, Irem FO, Iloanusi NI, Ezuma AD, Ezenwankwo FE, Okere PC, et al. Impact of physical exercises on immune function, bone mineral density, and quality of life in people living with HIV/AIDS: a systematic review with meta-analysis. BMC infectious diseases. 2019;19(1):340.

27. Patil R, Shimpi A, Rairikar S, Shyam A, Sancheti P. Effects of fitness training on physical fitness parameters and quality of life in human immunodeficiency virus-positive Indian females. Indian journal of sexually transmitted diseases and AIDS. 2017;38(1):47.

28. Gillespie JV. Health promotion and quality of life in HIV-1 infected individuals: The Ohio State University; 1997.

29. Rojas R, Schlicht W, Hautzinger M. Effects of exercise training on quality of life, psychological well-being, immune status, and cardiopulmonary fitness in an HIV-1 positive population. Journal of Sport and Exercise Psychology. 2003;25(4):440-55.

30. Evans S, Fishman B. Pain management training: a cognitive-behavioral approach to treating HIV-related peripheral neuropathy. Journal of Cognitive Psychotherapy. 1997;11(4):251-61.

31. Rosenfeld B, Breitbart W, McDonald MV, Passik SD, Thaler H, Portenoy RK. Pain in ambulatory AIDS patients. II: Impact of pain on psychological functioning and quality of life. Pain. 1996;68(2-3):323-8. 
32. Carver CS, Scheier MF, Weintraub JK. Assessing coping strategies: a theoretically based approach. Journal of personality and social psychology. 1989;56(2):267.

33. Keyes CL. Mental illness and/or mental health? Investigating axioms of the complete state model of health. Journal of consulting and clinical psychology. 2005;73(3):539.

34. Keyes CL. Subjective well-being in mental health and human development research worldwide: An introduction. Social indicators research. 2006;77(1):110.

35. Keyes CL, Michalec B. Viewing mental health from the complete state paradigm. A handbook for the study of mental health: Social contexts, theories, and systems. 2010:125-34.

36. Ammassari A, Antinori A, Cozzi-Lepri A, Trotta MP, Nasti G, Ridolfo AL, et al. Relationship between HAART adherence and adipose tissue alterations. Journal of acquired immune deficiency syndromes (1999). 2002;31:S140-4.

37. Blashill AJ, O'Cleirigh C, Mayer KH, Goshe BM, Safren SA. Body mass index, depression and sexual transmission risk behaviors among HIV-positive MSM. AIDS and Behavior. 2012;16(8):2251-6.

38. Collins E, Wagner C, Walmsley S. Psychosocial impact of the lipodystrophy syndrome in HIV infection. AIDS READER-NEW YORK-. 2000;10(9):546-51.

39. Power R, Tate H, McGill S, Taylor C. A qualitative study of the psychosocial implications of lipodystrophy syndrome on HIV positive individuals. Sexually transmitted infections. 2003;79(2):137-41.

40. Dudgeon WD, Phillips KD, Bopp CM, Hand GA. Physiological and psychological effects of exercise interventions in HIV disease. AIDS Patient Care and STDs. 2004;18(2):81-98.

41. Nobakht A, Mohraz M, Rahimzadeh M, Tehranizadeh M, Behboodi-Moghadam Z, Esmaelzadeh-Saeieh S. The effect of cognitive behavioural therapy on depression, anxiety, and stress in women with HIV. HIV and AIDS Review. 2018;17(3):218-23.

42. Horwath E. Psychiatric and neuropsychiatric manifestations of HIV infection. Journal of the International Association of Physicians in AIDS Care (Chicago, III: 2002). 2002;1:S1-15.

43. Jaggers JR, Hand GA, Dudgeon WD, Burgess S, Phillips KD, Durstine J, et al. Aerobic and resistance training improves mood state among adults living with HIV. International journal of sports medicine. 2015;36(02):175-81.

44. Orlando M, Burnam MA, Beckman R, Morton SC, London AS, Bing EG, et al. Re-estimating the prevalence of psychiatric disorders in a nationally representative sample of persons receiving care for HIV: results from the HIV cost and services utilization study. International Journal of Methods in Psychiatric Research. 2002;11(2):75-82.

45. Bhochhibhoya A, Qiao S, Mao Y, Zhou Y, Shen Z, Sui X, et al. Physical Activity, Depression, and Antiretroviral Therapy Adherence Among People Living With HIV: A Mediation Analysis. Journal of the Association of Nurses in AIDS Care. 2019;30(5):556-62.

46. Goodwin RD. Association between physical activity and mental disorders among adults in the United States. Preventive medicine. 2003;36(6):698-703.

47. Higgins JP, Green S. Cochrane handbook for systematic reviews of interventions: John Wiley \& Sons; 2011.

48. Akers J, Aguiar-Ibáñez R, Baba-Akbari SA. Systematic reviews: CRD's guidance for undertaking reviews in health care. University of York: Centre for Reviews and Dissemination; 2009.

49. Verhagen AP, de Vet HC, de Bie RA, Kessels AG, Boers M, Bouter LM, et al. The Delphi list: a criteria list for quality assessment of randomized clinical trials for conducting systematic reviews developed by Delphi consensus. Journal of clinical epidemiology. 1998;51(12):1235-41.

50. Aweto HA, Aiyegbusi Al, Ugonabo AJ, Adeyemo TA. Effects of aerobic exercise on the pulmonary functions, respiratory symptoms and psychological status of people living with HIV. Journal of research in health sciences. 2016;16(1):17-21.

51. Baigis J, Korniewicz DM, Chase G, Butz A, Jacobson D, Wu AW. Effectiveness of a home-based exercise intervention for HIV-infected adults: a randomized trial. Journal of the Association of Nurses in AIDS Care. 2002;13(2):33-45.

52. Chung CH, Lou VW. Effects of Supervised Exercise on Physical Health and Quality of Life Among Older Adults Living With HIV in Hong Kong. Journal of the Association of Nurses in AIDS Care. 2020;31(3):353-8.

53. Dianatinasab M, Fararouei M, Padehban V, Dianatinasab A, Alimohamadi Y, Beheshti S, et al. The effect of a 12-week combinational exercise program on CD4 count and mental health among HIV infected women: A randomized control trial. Journal of Exercise Science \& Fitness. 2018;16(1):21-5.

54. McDermott A, Zaporojan L, McNamara P, Doherty CP, Redmond J, Forde C, et al. The effects of a 16-week aerobic exercise programme on cognitive function in people living with HIV. AIDS care. 2017;29(6):667-74.

55. Ogalha C, Luz E, Sampaio E, Souza R, Zarife A, Neto MG, et al. A randomized, clinical trial to evaluate the impact of regular physical activity on the quality of life, body morphology and metabolic parameters of patients with AIDS in Salvador, Brazil. JAIDS Journal of Acquired Immune Deficiency Syndromes. 2011;57:S179-S85.

56. Oliveira VH, Rosa FT, Santos JC, Wiechmann SL, Narciso AM, de Moraes SMF, et al. Effects of a combined exercise training program on health indicators and quality of life of people living with HIV: a randomized clinical trial. AIDS and Behavior. 2020;24(5):1531-41.

57. Roos R, Myezwa H, van Aswegen H, Musenge E. Effects of an education and home-based pedometer walking program on ischemic heart disease risk factors in people infected with HIV: a randomized trial. JAIDS Journal of Acquired Immune Deficiency Syndromes. 2014;67(3):268-76.

58. Tiozzo E. The effect of combined moderate-intensity training on immune functioning, metabolic variables, and quality of life in HIV-infected individuals receiving highly active antiretroviral therapy: Citeseer; 2011.

59. Mutimura E, Stewart A, Crowther NJ, Yarasheski KE, Cade WT. The effects of exercise training on quality of life in HAART-treated HIV-positive Rwandan subjects with body fat redistribution. Quality of Life Research. 2008;17(3):377. 
60. Neidig JL, Smith BA, Brashers DE. Aerobic exercise training for depressive symptom management in adults living with HIV infection. Journal of the Association of Nurses in AIDS Care. 2003;14(2):30-40.

61. Maharaj SS, Chetty V. Rehabilitation program for the quality of life for individuals on highly active antiretroviral therapy in KwaZulu-Natal, South Africa: a short report. International Journal of Rehabilitation Research. 2011;34(4):360-5.

62. Ickovics JR, Hamburger ME, Vlahov D, Schoenbaum EE, Schuman P, Boland RJ, et al. Mortality, CD4 cell count decline, and depressive symptoms among HIV-seropositive women: longitudinal analysis from the HIV Epidemiology Research Study. Jama. 2001;285(11):1466-74.

63. Heissel A, Zech P, Rapp MA, Schuch FB, Lawrence JB, Kangas M, et al. Effects of exercise on depression and anxiety in persons living with HIV: A metaanalysis. Journal of psychosomatic research. 2019;126:109823.

64. Gomes Neto M, Ogalha C, Andrade AM, Brites C. A systematic review of effects of concurrent strength and endurance training on the health-related quality of life and cardiopulmonary status in patients with HIV/AIDS. BioMed research international. 2013;2013.

65. O'Brien K, Nixon S, Tynan AM, Glazier R. Aerobic exercise interventions for adults living with HIV/AIDS. Cochrane Database of Systematic Reviews. 2010(8).

66. O'Brien K, Tynan A-M, Nixon S, Glazier R. Effects of progressive resistive exercise in adults living with HIV/AIDS: systematic review and meta-analysis of randomized trials. Aids Care. 2008;20(6):631-53.

67. Nosrat S, Whitworth JW, Ciccolo JT. Exercise and mental health of people living with HIV: A systematic review. Chronic illness. 2017;13(4):299-319.

68. Patel K, Bid D, Thangamani R. Effectiveness of yoga asanas over conventional physiotherapy treatment on functional outcomes in patients with knee osteoarthritis. MOJ Yoga Physical Ther. 2018;3(3):54-7.

69. Kandola A, Ashdown-Franks G, Hendrikse J, Sabiston CM, Stubbs B. Physical activity and depression: towards understanding the antidepressant mechanisms of physical activity. Neuroscience \& Biobehavioral Reviews. 2019.

70. Lee H-J, Baek S-S. Role of exercise on molecular mechanisms in the regulation of antidepressant effects. Journal of Exercise Rehabilitation. 2017;13(6):617.

71. Pilar-Cuéllar F, Vidal R, Díaz A, Castro E, dos Anjos S, Pascual-Brazo J, et al. Neural plasticity and proliferation in the generation of antidepressant effects: hippocampal implication. Neural plasticity. 2013;2013.

72. Kim TH, Chang JS, Park K-S, Park J, Kim N, Lee Jl, et al. Effects of exercise training on circulating levels of Dickkpof-1 and secreted frizzled-related protein-1 in breast cancer survivors: A pilot single-blind randomized controlled trial. PLoS One. 2017;12(2):e0171771.

73. Tiwari SK, Agarwal S, Seth B, Yadav A, Nair S, Bhatnagar P, et al. Curcumin-loaded nanoparticles potently induce adult neurogenesis and reverse cognitive deficits in Alzheimer's disease model via canonical Wnt/ $\beta$-catenin pathway. ACS nano. 2014;8(1):76-103.

74. Saus E, Soria V, Escaramís G, Crespo J, Valero J, Gutiérrez-Zotes A, et al. A haplotype of glycogen synthase kinase $3 \beta$ is associated with early onset of unipolar major depression. Genes, Brain and Behavior. 2010;9(7):799-807.

75. Baek S-S, Jun T-W, Kim K-J, Shin M-S, Kang S-Y, Kim C-J. Effects of postnatal treadmill exercise on apoptotic neuronal cell death and cell proliferation of maternal-separated rat pups. Brain and Development. 2012;34(1):45-56.

76. Cerqueira JJ, Mailliet F, Almeida OF, Jay TM, Sousa N. The prefrontal cortex as a key target of the maladaptive response to stress. Journal of Neuroscience. 2007;27(11):2781-7.

77. Hutchison AJ, Breckon JD, Johnston LH. Physical activity behavior change interventions based on the transtheoretical model: a systematic review. Health Education \& Behavior. 2009;36(5):829-45.

78. Loughlan C, Mutrie N. Recruitment of sedentary NHS staff to a workplace exercise programme using an adapted stage of change questionnaire. Journal of Sports Science. 1995;13(1):64-5.

79. Di Bartolomeo G, Papa S. The effects of physical activity on social interactions: The case of trust and trustworthiness. Journal of Sports Economics. 2019;20(1):50-71.

80. O'donoghue G, Perchoux C, Mensah K, Lakerveld J, Van Der Ploeg H, Bernaards C, et al. A systematic review of correlates of sedentary behaviour in adults aged 18-65 years: a socio-ecological approach. BMC public health. 2016;16(1):163.

81. Crawford A, Hollingsworth HH, Morgan K, Gray DB. People with mobility impairments: Physical activity and quality of participation. Disability and health journal. 2008;1(1):7-13.

82. Kim M, Cho K, Lee W. Community walking training program improves walking function and social participation in chronic stroke patients. The Tohoku journal of experimental medicine. 2014;234(4):281-6.

83. Vancampfort D, Stubbs B, De Hert M, du Plessis C, Gbiri CAO, Kibet J, et al. A systematic review of physical activity policy recommendations and interventions for people with mental health problems in Sub-Saharan African countries. The Pan African Medical Journal. $2017 ; 26$.

84. Chan JS, Liu G, Liang D, Deng K, Wu J, Yan JH. Special issue-therapeutic benefits of physical activity for mood: a systematic review on the effects of exercise intensity, duration, and modality. The Journal of psychology. 2019;153(1):102-25.

85. Peluso MAM, Andrade LHSGd. Physical activity and mental health: the association between exercise and mood. Clinics. 2005;60(1):61-70.

86. Salmon P. Effects of physical exercise on anxiety, depression, and sensitivity to stress: a unifying theory. Clinical psychology review. 2001;21(1):33-61.

87. O’Brien KK, Ibáñez-Carrasco F, Solomon P, Harding R, Cattaneo J, Chegwidden W, et al. Advancing research and practice in HIV and rehabilitation: a framework of research priorities in HIV, disability and rehabilitation. BMC infectious diseases. 2014;14(1):724.

88. Fortwengel G, Ibeneme S, Behnsen J, Heinrich L, llenseer S, Kirchner S, et al. Association of Education and Knowledge of HIV with HIV Stigma in Thirteen Selected African Countries. Central African Journal of Public Health. 2018;4(2):48-58.

Page $15 / 23$ 
89. Varas-Díaz N, Serrano-García I, Toro-Alfonso J. AIDS-related stigma and social interaction: Puerto Ricans living with HIV/AIDS. Qualitative health research. 2005;15(2):169-87.

90. Knapen J, Vancampfort D, Moriën Y, Marchal Y. Exercise therapy improves both mental and physical health in patients with major depression. Disability and rehabilitation. $2015 \mathrm{Jul}$ 31;37(16):1490-5.

91. Dianatinasab M, Ghahri S, Dianatinasab A, Amanat S, Fararouei M. Effects of Exercise on the Immune Function, Quality of Life, and Mental Health in HIV/AIDS Individuals. InPhysical Exercise for Human Health 2020 (pp. 411-421). Springer, Singapore.

92. Faraone SV. Interpreting estimates of treatment effects: implications for managed care. Pharmacy and Therapeutics. 2008 Dec;33(12):700.

93. Ibeneme SC, Nwosu A, Anyachukwu CC, Ibeneme GC, Bakare MO, Fortwengel G, Limaye D. Burden and factors associated with post-stroke depression in East central Nigeria. African health sciences. 2017;17(3):859-67.

94. Ibeneme SC, Omeje C, Myezwa H, Ezeofor SN, Anieto EM, Irem F, Nnamani AO, Ezenwankwo FE, Ibeneme GC., (2019). Effects of physical exercises on inflammatory biomarkers and cardiopulmonary function in patients living with HIV: a systematic review with meta-analysis. BMC Infectious Diseases, $19(1)$, p.359 - 381

\section{Tables}

Table 1: Characteristics of Included Studies 


\begin{tabular}{|c|c|c|c|c|c|c|c|}
\hline $\begin{array}{l}\text { or, } \\
\text { r) } \\
\text { tion of } \\
y\end{array}$ & $\begin{array}{l}\text { Disease stage } \\
\text { ART Status } \\
\text { Age range } \\
\text { Gender } \\
\text { Sample size } \\
\text { (N) } \\
\text { Retention } \\
\text { (attrition) }\end{array}$ & $\begin{array}{l}\text { Intervention Group } \\
\text { No of participants allocated (No } \\
\text { that completed) } \\
\text { Adherence rate }\end{array}$ & $\begin{array}{l}\text { Duration of } \\
\text { intervention }\end{array}$ & $\begin{array}{l}\text { Control Group } \\
\text { No of participants } \\
\text { allocated (No that } \\
\text { completed) }\end{array}$ & $\begin{array}{l}\text { Outcome } \\
\text { Parameter } \\
\text { Interest }\end{array}$ & $\begin{array}{l}\text { Measurement } \\
\text { tool for } \\
\text { outcome }\end{array}$ & $\begin{array}{l}\text { Summary } \\
\text { result }\end{array}$ \\
\hline $\begin{array}{l}g \quad \& \\
\text { (2019) } \\
\text { I Kong }\end{array}$ & $\begin{array}{l}\text { NR } \\
\text { On ART } \\
56-84 y r s \\
\text { Male(16), } \\
\text { Female (5) } \\
\text { N=21 } \\
95.24 \% \\
(4.76 \%)\end{array}$ & $\begin{array}{l}\text { 45mins of supervised combined } \\
\text { aerobic and resistance training each } \\
\text { at a moderate intensity of } 50-70 \% \\
\text { MHR, } 2 \text { sessions per week for } 8 \\
\text { weeks. } \\
11(10) \\
96.3 \%\end{array}$ & 8 weeks & $\begin{array}{l}\text { Unsupervised exercise. } \\
\text { Advised to continue } \\
\text { routine daily activities } \\
\text { and self-exercise. } \\
10(10)\end{array}$ & $\begin{array}{l}\text { Social } \\
\text { functioning/social } \\
\text { participation }\end{array}$ & $\begin{array}{l}\text { The social } \\
\text { functioning } \\
\text { domain of SF- } \\
36 \text { MOS }\end{array}$ & $\begin{array}{l}\text { Improved } \\
\text { physical } \\
\text { functioning may } \\
\text { result in better } \\
\text { self-image and } \\
\text { confidence in } \\
\text { social life. These } \\
\text { were reflected in } \\
\text { the improvement } \\
\text { seen in social } \\
\text { functioning } \\
\text { domain scores of } \\
\mathrm{SF}-36 \mathrm{MOS} \text { used } \\
\text { in this study } \\
(\mathrm{p}=0.043) \text {. }\end{array}$ \\
\hline $\begin{array}{ll}\text { ira } & \text { et } \\
\text { :019) } & \\
\text { il } & \end{array}$ & $\begin{array}{l}\text { NR } \\
\text { On ART } \\
\text { 18-60yrs } \\
\text { Male (21), } \\
\text { Female(25) } \\
\mathrm{N}=46 \\
50 \%(50 \%)\end{array}$ & $\begin{array}{l}\text { 15-20mins of supervised combined } \\
\text { exercise training (CET): } \\
\text { (Aerobic exercise: } 15-20 \text { mins of } \\
\text { moderate-intensity at } 50 \%-65 \% \\
\text { HRR). } \\
\text { (Strength training: } 15-20 \text { mins of } 8 \text { - } \\
\text { 15MR of } 2-3 \text { sets). } \\
3 \text { sessions per week for } 16 \text { weeks. } \\
n=25 \text { (14) } \\
87.4 \%\end{array}$ & 16 weeks & $\begin{array}{l}\text { Recreational session } \\
\text { consisting of stretches, } \\
\text { gaming and dancing }\end{array}$ & $\begin{array}{l}\text { Depression } \\
\text { and } \\
\text { Social } \\
\text { Functioning/Social } \\
\text { Participation }\end{array}$ & $\begin{array}{l}\text { Becks } \\
\text { Depression } \\
\text { Inventory } \\
\text { and } \\
\text { The social } \\
\text { functioning } \\
\text { subscale of } \\
\text { WHOQOL-HIV }\end{array}$ & $\begin{array}{l}\text { There was an } \\
\text { improvement in } \\
\text { depression } \\
(\mathrm{p}<0.05) \text {, but not } \\
\text { in the social } \\
\text { functioning } \\
\text { domain of quality } \\
\text { of life in this } \\
\text { study following } \\
\text { the 16-week of } \\
\text { CET. }\end{array}$ \\
\hline
\end{tabular}

\begin{tabular}{|c|c|c|c|c|c|}
\hline $\begin{array}{l}\text { atinasab } \\
(2018)\end{array}$ & $\begin{array}{l}\text { NR } \\
\text { NR } \\
20-40 y r s \\
\text { Women } \\
\text { N=40 } \\
75 \%(25 \%)\end{array}$ & $\begin{array}{l}\text { Supervised Combinational exercise } 12 \text { weeks } \\
\text { (Aerobic exercise: } 45 \text { mins at } 40-45 \% \\
\text { MHR). } \\
\text { (Strengthening exercise: } 15 \text { mins of } \\
3 \text { sets of } 8 \text { repetitions at } 50-55 \% \\
\text { RM). } \\
3 \text { sessions per week for } 12 \text { weeks. } \\
\text { Plus VCT's routine services. } \\
n=20(14) \\
\text { NR }\end{array}$ & VCT's routine services depression & GHQ-28 & $\begin{array}{l}\text { Aerobic and } \\
\text { resistance } \\
\text { exercises had a } \\
\text { positive effect on } \\
\text { mental health } \\
\text { indices (severe } \\
\text { depression) of } \\
\text { HIV positive } \\
\text { female patients } \\
(\mathrm{p}=0.008) \text {. }\end{array}$ \\
\hline
\end{tabular}

ərmott NR

6) NR

nd 18-65yrs

Male(8),

Female(3)

$\mathrm{NR}(2)$

$\mathrm{N}=13$

$84.6 \%(15.4 \%)$

o et al, Asymptomatic, 30mins of supervised aerobic 6 weeks

j) non-AIDS and exercise at $50-60 \%$ HRR on a cycle

ria symptomatic, ergometer, 3 sessions per week for

non-AIDS HIV 6 weeks.

patients

$\begin{array}{ll} & \mathrm{n}=20(18) \\ \text { On HAART } & \mathrm{NR}\end{array}$

18 yrs and

above

Male(15),

Female(25)

$\mathrm{N}=40$

$84.5 \%(15.5 \%)$

ərs et al, Asymptomatic

5) (63\%),

Symptomatic

$(10 \%)$, AIDS

The total duration of $50 \mathrm{mins}$ of 6 weeks supervised combined aerobic and

resistance training.

patients
$31-52 \mathrm{~min}$ of 2 supervised and 1
unsupervised (recorded in a diary by participants) aerobic exercise ergometer, and cross-trainer.

3 sessions per week at $40-75 \%$

$\mathrm{n}=6(5)$

$60 \%$ training on a treadmill, cycle
No exercise was advice Physical Activity to continue with their level daily routine.

$\mathrm{n}=7$ (6)
Actigraph

GT3X+Tri Axis Accelerometer

There was no significant change Physical Activity level.
No therapeutic exercise Depression only had 30mins session of counselling once in 2 weeks.

$\mathrm{n}=20$ (15)
Engaged in a sedentary Depression lifestyle

$\mathrm{n}=47(23) \quad 3$ missing

data
BDI

Comparisons

between the pretest and post-test depression mean score of the study group and between the study group and the control group showed that there significant improvement $(\mathrm{p}=0.001)$. 
(25\%),

(Resistance training: 20mins of 1

Missing report set, 12 repetitions)

$(2 \%) \quad 2$ sessions per week for 6 weeks.

36

$\mathrm{n}=46(26) 2$ missing data

Participants

NR

on ART

18 and 0lder

Male(37),

Female(12)

NR(44)

$\mathrm{N}=93$

$52.69 \%$

(47.31\%)

is et al, NR

4)

h Africa On HAART

20-65yrs

Male(18),

Female (66)

$\mathrm{N}=84$

(60.7\%) $39.3 \%$

started at 1000 steps per day from

participants' baseline step count finding at 3 times per week.

This step count was adjusted with additional 500 steps every 2 weeks when participants attained their preceding goal until a value of 3000 steps from baseline was achieved. After reaching the 3000 step count goal, frequency per week was

adjusted from 3 to 4 to 5 times per week only if participants reached their previously determined frequency and managed well without physical complaints.

$42(29)$

$72.4 \%$

$\begin{array}{ll}\begin{array}{l}\text { araj \& } \\ \text { ty, }\end{array} & \\ \text { 1) } \\ \text { h Africa } & \text { On HAART } \\ & 18 \text { and older }\end{array}$

The total duration of $40 \mathrm{~min}$.

Supervised aerobic exercise: on a cycle ergometer and treadmill for 20 mins each with a rest period of $20 \mathrm{mins}$ each with a rest period
$20 \mathrm{~min}$ once a week for 12 weeks.

Male(34),

Home programme: 10mins of brisk

Female(18)

walking, squatting and jogging 3

$\mathrm{N}=52$

$26(20)$

$69 \%(31 \%)$ intensity

exercise

intervention

showed

significant

reduction in selfreported

depression $(\mathrm{p}=$ 0.03 )
12 weeks

20 mins of Heat therapy
on the thigh muscles

using thigh muscles

plus

reading of magazines

at home for 30mins 3

times per week for 12

weeks

26(16) group Physical Activity Yamax SW200 Although the 12standard clinic received 1 phone call monthly from

determine health status.

$42(22)$

Social
punctioning/Social
participation

The social There is a functioning significant domain of SF- increase in the 36 MOS social function domain of Quality of Life $(\mathrm{p}=0.022)$.

These findings imply that successful participation and association with a rehabilitation program were associated with a positive mental status leading to functional physical improvement and social well-being

One hour monthly Social discussion on functioning/Social nutritional needs and participation recommendation the importance of the regular physical activity. hysical

35(28)

Female(29)

(Gender of 7 dropouts in

the control group was not reported)

$\mathrm{N}=70$

$90 \%(10 \%)$

so, NR

On HAART

10-50mins of aerobic exercise at 60
Supervised Combined Aerobic and 12 weeks Resistance Exercise Training (CARET): of $15-20$ repetitions at $60-75 \% 1 \mathrm{RM}$ and resistance exercises of 1 set 8-

24weeks monthly nutritional counselling 3

\section{$35(35)$}$$
\text { r }
$$

and resistance exercises of 1 set 8 


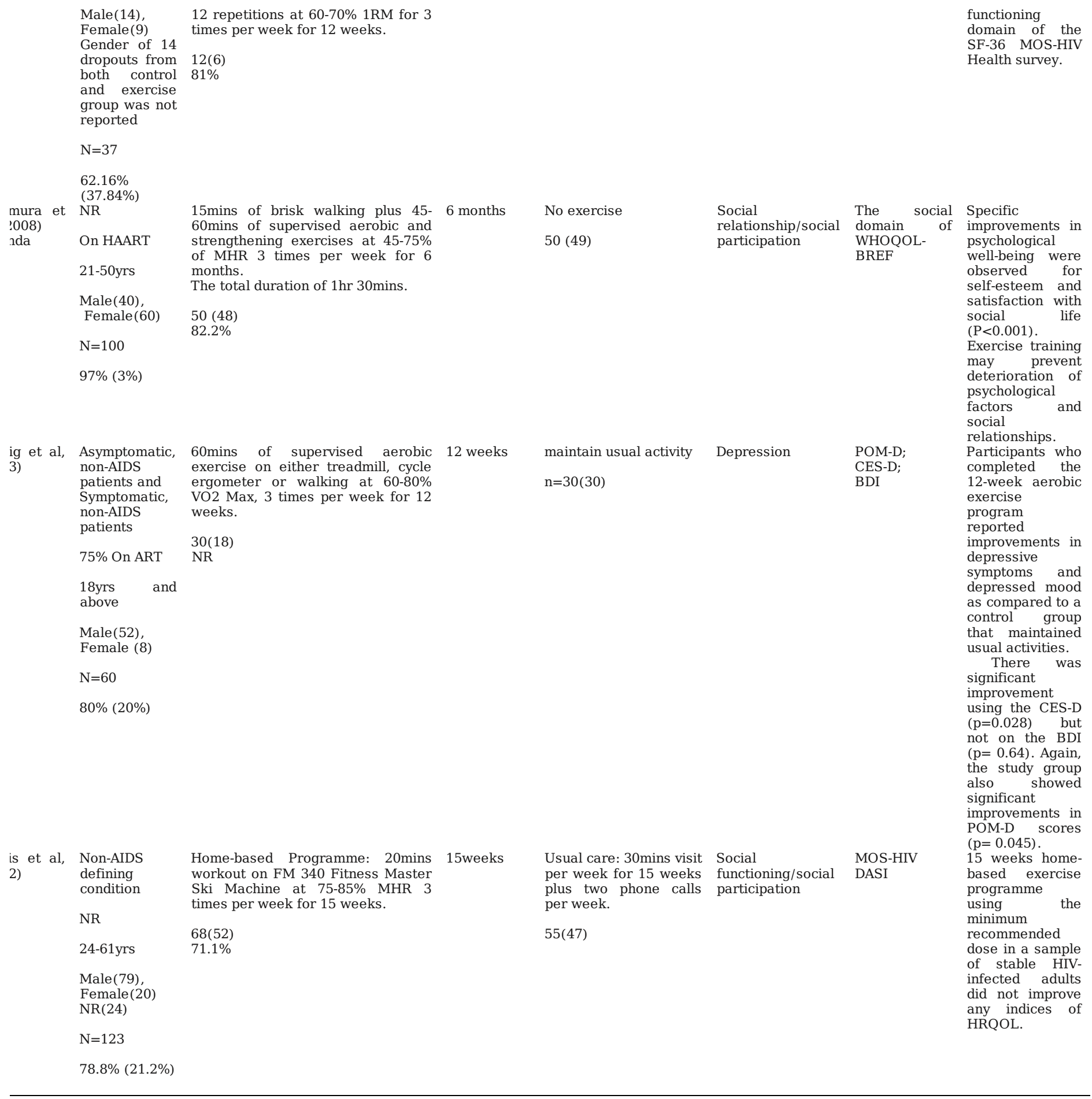

Table 2: A Quality appraisal using the PEDro scale 


\begin{tabular}{|c|c|c|c|c|c|c|c|c|c|c|}
\hline Study & $\begin{array}{l}\text { Random } \\
\text { allocation }\end{array}$ & $\begin{array}{l}\text { Concealed } \\
\text { allocation }\end{array}$ & $\begin{array}{l}\text { Baseline } \\
\text { comparability }\end{array}$ & $\begin{array}{l}\text { Blinding } \\
\text { of } \\
\text { subjects }\end{array}$ & $\begin{array}{l}\text { Blinding of } \\
\text { Therapists }\end{array}$ & $\begin{array}{l}\text { Blinding } \\
\text { of } \\
\text { assessor }\end{array}$ & $\begin{array}{l}\text { Adequate } \\
\text { follow-up }\end{array}$ & $\begin{array}{l}\text { Intention } \\
\text { to treat } \\
\text { analysis }\end{array}$ & $\begin{array}{l}\text { Between- } \\
\text { group } \\
\text { comparison }\end{array}$ & $\begin{array}{l}\text { Point } \\
\text { estimates } \\
\text { and } \\
\text { variability }\end{array}$ \\
\hline $\begin{array}{l}\text { Chung et al } \\
2019\end{array}$ & Yes & No & No & No & No & No & Yes & No & Yes & Yes \\
\hline $\begin{array}{ll}\text { Oliveira } & \text { et } \\
\text { al } 2019 & \end{array}$ & Yes & No & No & No & No & No & No & No & Yes & Yes \\
\hline $\begin{array}{l}\text { Dianastinab } \\
\text { et al } 2018\end{array}$ & Yes & No & Yes & No & No & No & No & No & Yes & Yes \\
\hline $\begin{array}{l}\text { McDemortt } \\
\text { et al } 2016\end{array}$ & Yes & No & Yes & No & No & No & Yes & No & Yes & Yes \\
\hline $\begin{array}{l}\text { Aweto et al } \\
2016\end{array}$ & Yes & No & Yes & No & No & No & No & No & Yes & Yes \\
\hline $\begin{array}{ll}\text { Jaggers } & \text { et } \\
\text { al } 2015 & \end{array}$ & Yes & No & Yes & No & No & No & No & No & Yes & Yes \\
\hline $\begin{array}{l}\text { Roos et al } \\
2014\end{array}$ & Yes & Yes & Yes & No & No & Yes & No & Yes & Yes & Yes \\
\hline $\begin{array}{l}\text { Ogalha et al } \\
2011\end{array}$ & Yes & No & Yes & No & No & No & Yes & No & Yes & Yes \\
\hline $\begin{array}{l}\text { Maharaj et } \\
\text { al 2011 }\end{array}$ & Yes & No & Yes & No & No & Yes & No & Yes & Yes & Yes \\
\hline Tiozzo 2011 & Yes & No & Yes & No & No & No & No & No & Yes & Yes \\
\hline $\begin{array}{l}\text { Mutimura } \\
\text { et al } 2008\end{array}$ & Yes & No & Yes & No & No & No & Yes & No & Yes & Yes \\
\hline $\begin{array}{l}\text { Baigis et al } \\
2002\end{array}$ & Yes & Yes & Yes & No & No & No & No & Yes & No & Yes \\
\hline $\begin{array}{l}\text { Nedig et al } \\
2003\end{array}$ & Yes & No & Yes & No & No & No & No & No & Yes & Yes \\
\hline
\end{tabular}

Table 3: Outcome values for Depression

\begin{tabular}{|c|c|c|}
\hline & Timepoint & Depression (measurement tool) \\
\hline z et al., 2019 & $\begin{array}{l}\text { Immediately } \\
\text { Intervention }\end{array}$ & $\begin{array}{l}\text { Minimal depression }-\left\{\text { Int. }{ }^{*}\left(5 \text { (55.6) vs Cont. }{ }^{*}(13(92.9)) ; \mathrm{p}<0.05 ; \mathrm{d}=0.01\right\} \text { (BDI) }\right. \\
\text { Mild, Moderate or Severe depression - }\{\text { Int. }(1(7.1)) \text { vs Cont. }(4(44.4)) ; \mathrm{p}<0.005 \text {; } \\
d=0.17\} \text { (BDI) }\end{array}$ \\
\hline tinab et al., & $\begin{array}{l}\text { Immediately } \\
\text { Intervention }\end{array}$ & $\begin{array}{l}\left.\begin{array}{l}\text { Int. }(2.69 \pm 1.44) \\
\text { Depression) }\end{array} \text { vs Cont. }(7.60 \pm 5.38) ; \mathrm{p}=0.008 ; \mathrm{d}=\mathrm{NR}\right\} \text { (GHQ-28-Severe }\end{array}$ \\
\hline et al., 2016 & & $\{$ Int. (3.50 \pm 1.27$)$ vs Cont. $(8.33 \pm 5.80) ; \mathrm{p}=0.001 ; \mathrm{d}=\mathrm{NR}\}$ (BDI) \\
\hline ; et al., 2015 & $\begin{array}{l}\text { Immediately } \\
\text { Intervention }\end{array}$ & $\{$ Int. $(6.21 \pm 1.50 \square$ vs Cont. $(8.2 \pm 2.08$; $\mathrm{p}<0.05 ; \mathrm{d}=\mathrm{NR}\}($ POM-D) \\
\hline t al., 2003 & $\begin{array}{l}\text { Immediately } \\
\text { Intervention }\end{array}$ & $\begin{array}{l}\text { \{Int. }(6.1 \pm 8.9) \text { vs Cont. }(10.9 \pm 11.2) ; \mathrm{p}=0.045 ; \mathrm{d}=\mathrm{NR}\} \text { (POM-D) } \\
\text { \{Int. }(7.2 \pm 7.1) \text { vs Cont. }(14.1 \pm 11.3) ; \mathrm{p}=0.028 ; \mathrm{d}=\mathrm{NR}\} \text { (CES-D) } \\
\text { \{Int. }(5.6 \pm 6.3) \text { vs Cont. }(8.7 \pm 7.1) ; \mathrm{p}=\mathrm{NS} ; \mathrm{d}=\mathrm{NR}\}(\mathrm{BDI})\end{array}$ \\
\hline
\end{tabular}

Int $=$ Intervention group; Cont $=$ Control group; $\mathrm{p}=\mathrm{p}$-value; $\mathrm{d}=$ effect size; Except otherwise stated, outcomes are reported as: [Int (Mean \pm $\mathrm{SD})$ vs Cont (Mean $\pm \mathrm{SD})$; p-value; d (effect size)].

*Values are reported as [Int. absolute(relative) scores vs Cont. absolute(relative) scores; p-value; d (effect size)].

Treported as Standard Error (SE).

BDI= Becks Depression Inventory; GHQ-28-Severe Depression= General Health Questionnaire-Severe Depression Sub-scale score; POM-D=

Profile of Mood Scale- depression score; CES-D= Center for Epidemiological Studies-Depression scale

Table 4: Outcome values for PA level Post Intervention

\begin{tabular}{|c|c|c|}
\hline Study & Timepoint & Physical activity level (Unit of measurement) \\
\hline $\begin{array}{l}\text { McDermott et al., } \\
2016\end{array}$ & Immediately post Intervention & $\begin{array}{l}\mathrm{LPA}=\{\text { Int }(34.3 \pm 13.5) \text { vs Cont. }(27.9 \pm 8.5) ; \mathrm{p}=\mathrm{NS} ; \mathrm{d}=\mathrm{NR}\} \text { (Accelerometer } \\
\text { hours/week) } \\
\text { MPA }=\{\text { Int }(4.1 \pm 3.2) \text { vs Cont. }(3.8 \pm 1.2) ; \mathrm{p}=\mathrm{NS} ; \mathrm{d}=\mathrm{NR}\} \text { (Accelerometer } \\
\text { hours/week) } \\
\text { VPA }=\{\text { Int }(0.5 \pm 0.8) \text { vs Cont. }(0.1 \pm 0.1) ; \mathrm{p}=\mathrm{NS} ; \mathrm{d}=\mathrm{NR}\} \text { (Accelerometer } \\
\text { hours/week) }\end{array}$ \\
\hline Roos et al 2014 & $\begin{array}{l}\text { Immediately post-intervention at } \\
12 \text { months }\end{array}$ & 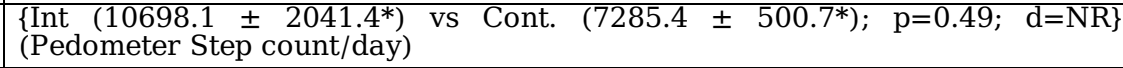 \\
\hline
\end{tabular}

Int = Intervention group; Cont. = Control group; $\mathrm{p}=\mathrm{p}$-value; $\mathrm{d}=$ effect size; LPA= Light Physical Activity; MPA= Moderate Physical Activity, VPA= Vigorous Physical Activity.

Except otherwise stated, outcomes are reported as:

[Int (Mean \pm SD) vs Cont. (Mean \pm SD); p-value; d (effect size)] 
* outcome reported as Standard Error.

Table 5: Outcome values for Social Participation

\begin{tabular}{|c|c|c|}
\hline Study & Timepoint & Social Functioning/Social Participation (measurement tool - domain) \\
\hline Chung \& Lou., 2019 & $\begin{array}{l}\text { Immediately } \\
\text { Intervention }\end{array}$ & $\begin{array}{l}\{\text { Int (97.50 } \pm 5.27) \text { vs cont. }(81.25 \pm 16.93) ; \mathrm{p}=0.043 ; \mathrm{d}=\mathrm{NR}\} \quad \text { (SF-36 - Social } \\
\text { domain) }\end{array}$ \\
\hline Oliveira et al., 2019 & $\begin{array}{l}\text { Immediately } \\
\text { Intervention }\end{array}$ & $\begin{array}{l}\{\text { Int }(15.0 \pm 2.4) \text { vs cont. }(13.9 \pm 2.9) ; \mathrm{p}=\mathrm{NS} ; \mathrm{d}=0.07\} \text { (WHOQOL-HIV - Social } \\
\text { domain) }\end{array}$ \\
\hline Maharaj et al., 2011 & $\begin{array}{l}\text { Immediately } \\
\text { Intervention }\end{array}$ & $\{$ Int $(70.2 \pm 18.9)$ vs cont. $(66.8 \pm 14.4) ; \mathrm{p}=0.022 ; \mathrm{d}=\mathrm{NR}\}$ (SF-36 - Social domain) \\
\hline Ogalha et al., 2011 & $\begin{array}{l}\text { Immediately } \\
\text { intervention }\end{array}$ & $\{$ Int (91.8 \pm 31.6$)$ vs cont. $(94.0 \pm 10.9) ; \mathrm{p}=0.001 ; \mathrm{d}=\mathrm{NR}\}$ (SF-36 - Social domain) \\
\hline Tiozzo., 2011 & $\begin{array}{l}\text { Immediately } \\
\text { intervention }\end{array}$ & $\{$ Int (81.3 \pm 20.9$)$ vs cont. $(86.1 \pm 26.1) ; \mathrm{p}=\mathrm{NS} ; \mathrm{d}=\mathrm{NR}\}$ (SF-36 - Social domain) \\
\hline $\begin{array}{l}\text { Mutimura et al., } \\
2008\end{array}$ & $\begin{array}{l}\text { Immediately } \\
\text { intervention }\end{array}$ & $\{$ Int $(9.8 \pm 0.7)$ vs cont. $(9.0 \pm 0.5) ; \mathrm{p}<0.001 ; \mathrm{d}=\mathrm{NR}\}$ (WHOQOL-HIV- Social domain) \\
\hline Fillipas et al., 2006 & $\begin{array}{l}\text { Immediately } \\
\text { intervention }\end{array}$ & $\{$ Int (43.2 \pm 87.2$)$ vs cont. (69.0 \pm 38.7$) ; \mathrm{p}=\mathrm{NS} ; \mathrm{d}=\mathrm{NR}\}$ (MOS-HIV - social domain) \\
\hline Baigis et al., 2002 & $\begin{array}{l}\text { Immediately } \\
\text { intervention }\end{array}$ & $\{$ Int (88.4 \pm 22.1$)$ vs Cont. (84.9 \pm 21.2$) ; \mathrm{p}=\mathrm{NS} ; \mathrm{d}=0.57\}$ (MOS-HIV - social domain) \\
\hline
\end{tabular}

Int $=$ Intervention group; Cont $=$ Control group; $p=p$-value; $d=$ effect size; Except otherwise stated, outcomes are reported as: [Int $($ Mean $\pm \mathrm{SD})$ vs Cont (Mean $\pm \mathrm{SD})$; $\mathrm{p}$-value; $\mathrm{d}$ (effect size)].

SF-36= Short Form 36; WHOQOL-HIV= World Health Organisation Quality of Life HIV Health Survey; MOS-HIV = Medical Outcomes Study-HIV Health Survey.

\section{Figures}

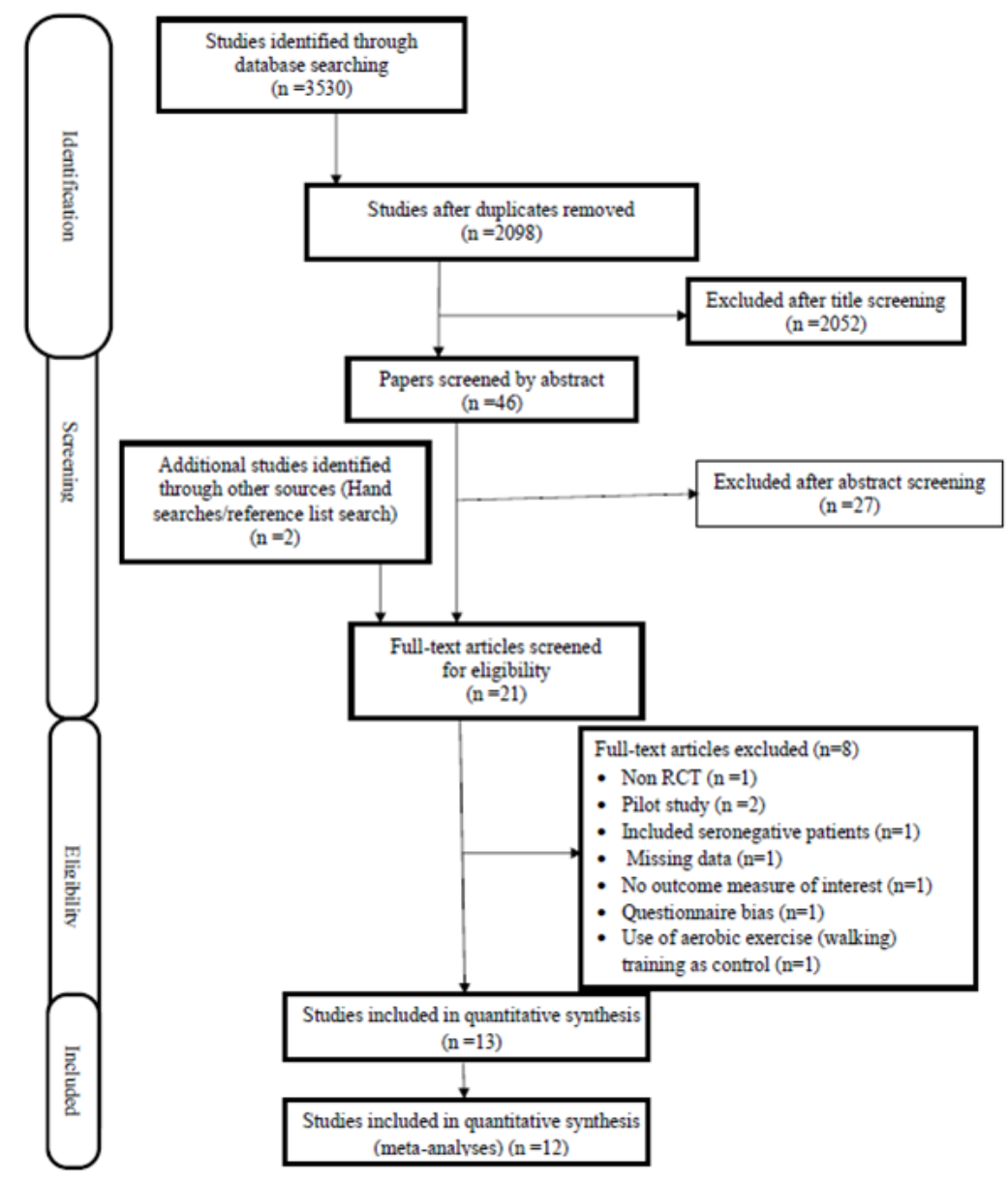

Figure 1

PRISMA diagram for mental health, physical activity level, social participation 


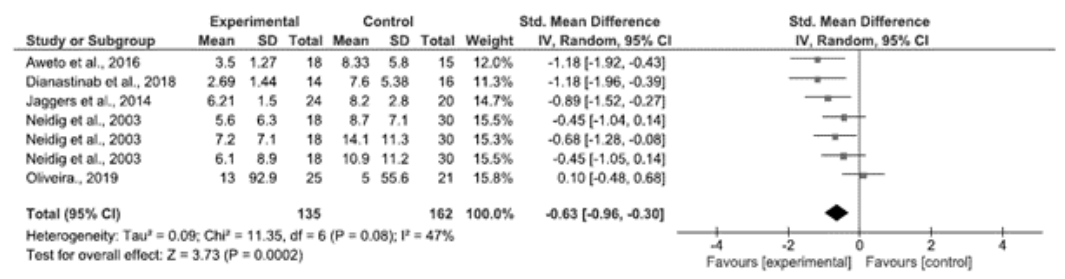

Figure 2

Forest plot for Depression - meta-analysis of five studies

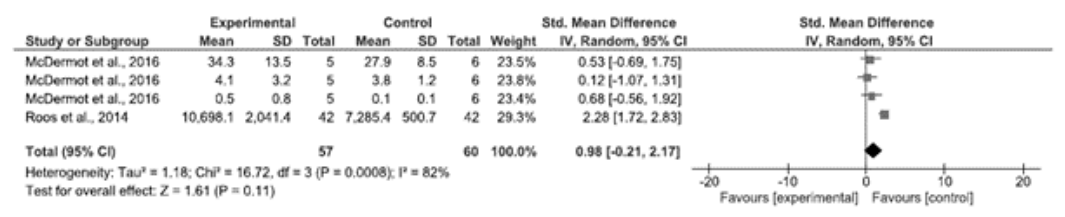

Figure 3

Forest plot for physical activity level - meta-analysis of two studies

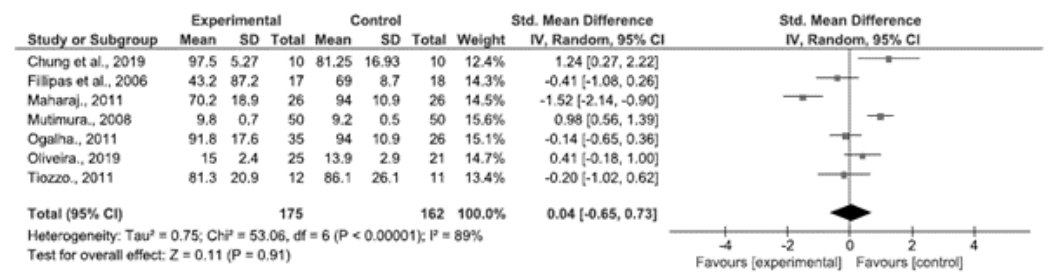

\section{Figure 4}

Forest plot for social participation - meta-analysis of seven studies

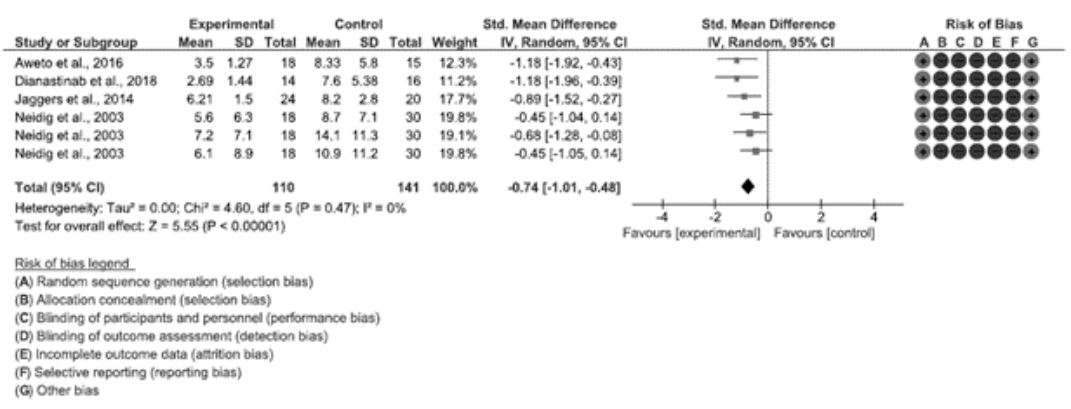

Figure 5

Sensitivity analysis for depression - secondary meta-analysis of four studies

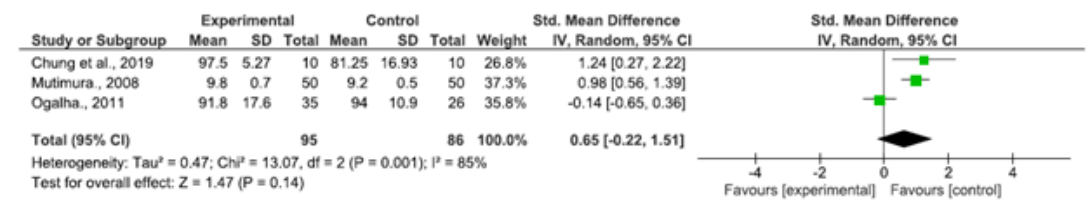

Figure 6 
Sensitivity analysis for social participation - secondary meta-analysis of four studies

\section{Supplementary Files}

This is a list of supplementary files associated with this preprint. Click to download.

- searchstrategySR11.docx

- PRISMA2009Checklist.doc 